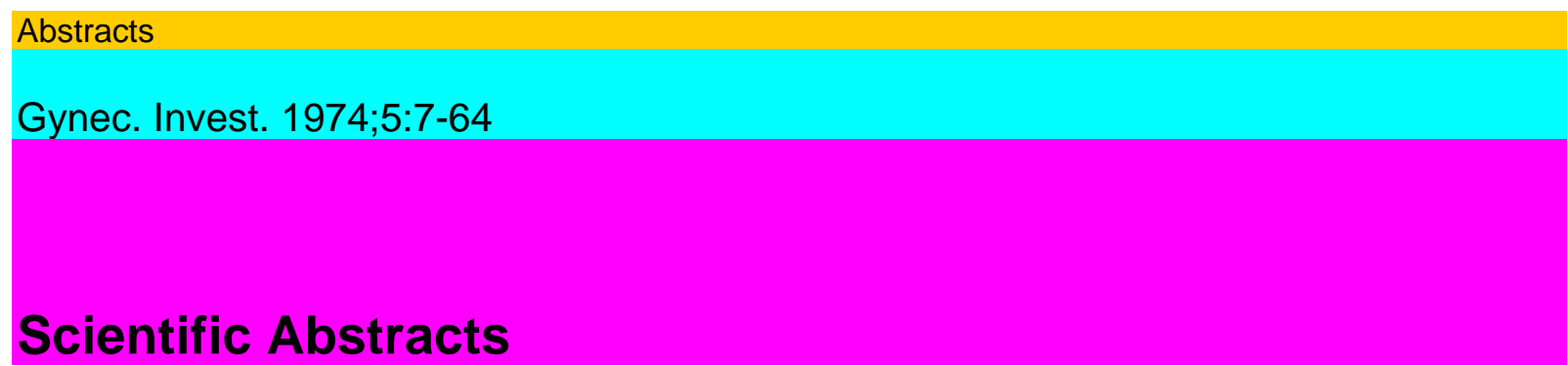

1 Systemic and Pulmonary Hemodynamic Resposes to Neurotransmitters during Fetal

Development

B. Nuwayhid, C. Brinkman, III, J. Bevan, C. Su and N.S. Assali

Department of Obstetrics-Gynecology and Pharmacology, University of California, Los

Angeles, Calif., USA

Development of vascular receptors in pulmonary and systemic circulations and their reactivity to neurotransmitters were investigated in fetal lambs between 60 days and term gestation (300$5,800 \mathrm{~g}$ ), in chronic and acute experiments. Changes in heart rate, pulmonary and systemic pressures, resistances and flows were monitored before and after administration of a- and /3adrenergic (norepinephrine, epinephrine, isoproterenol) and cholinergic (acetylcholine) neurotransmitters. Results show: (a) $\beta$-adrenergic receptors are present in fetal heart as early as 60 days' gestation and their chronotropic and inotropic responses to neurotransmitters increases with fetal age; (b) $\alpha$-adrenergic receptors are present predominantly in systemic vascular bed at 60 days' gestation and their pressor response increases with fetal maturity; (c) cholinergic receptors are present predominantly in the pulmonary vascular bed and the ductus arteriosus, and their stimulation with acetylcholine produces pulmonary vasodilatation and ductus constriction, the magnitude of which increases with fetal maturity; the changes in the systemic circulation are secondary to those occurring in the pulmonary circulation. Conclusion: (1) although reñexes mediating cholinergic and adrenergic impulses become active in controlling fetal circulation at different periods of development, vascular receptors are already developed in immature fetuses and their reactivity increases with fetal age; (2) fetal pulmonary circulation is extremely responsive to cholinergic neurotransmitters in contrast to adult circulation; the reason is probably related to the difference in the status of pulmonary vascular resistance in the fetus and adult. 2 Amniotic Fluid Cyclic AMP in Pregnancy Complicated by Hypertension

William Y. Ling, John M. Marsh, William N. Spellacy and William J. LeMaire Departments of Pediatrics, Biochemistry, and Obstetrics-Gynecology, and the Endocrine Laboratory, University of Miami, School of Medicine, Miami, Fla., USA

The study of various amniotic fluid constituents has been used as a direct approach to fetal prognosis. Accordingly, we investigated the possible relationship between the fluid cyclic AMP (cAMP) content and fetal well-being. Using a competitive protein binding assay, cAMP was measured in amniotic fluids from late stages of normal pregnancy and from pregnancy complicated by mild and severe forms of preeclampsia and chronic hypertension. In addition, the corresponding creatinine concentration, L/S ratio, and maternal serum $\mathrm{hPL}$ level were also evaluated. The cAMP level (mean \pm SD) in the fluids from hypertensive Society for Gynecologic Investigation 8

patients $(57.1 \pm 12.0 \mathrm{p} \Lambda \mathrm{f} / \mathrm{ml})$ was significantly higher $(\mathrm{p}<0.001)$ than normal value $(19.3 \pm 5.0$ $\mathrm{p} \Lambda \mathrm{f} / \mathrm{ml}$ ). Preeclampsia, which occurs only during pregnancy, afforded two unique observations: (a) cAMP level in the severe cases $(79.0 \pm 16.8 \mathrm{pM} / \mathrm{ml})$ was markedly higher than that in chronic 
hypertension $(51.5 \pm 12.6 \mathrm{pM} / \mathrm{ml})$, and (b) there was a positive correlation between cAMP levels and the highest diastolic blood pressures recorded during pregnancy $(r=0.902, p<0.001)$. The data show that hypertension in pregnancy leads to an elevation of fluid cAMP, and that in preeclampsia, a positive correlation exists between cAMP level and the increasing clinical severity of the syndrome. Thus, analysis of the amniotic fluid cAMP may be a useful tool for the assessment of the severity of preeclampsia, and for fetal prognosis.

(Supported by NIH grants: RR 05363, HD 03142, HL 14141, Ford Foundation grant 0338, and United Funds of Dade County.)

3 A Clinically Useful Simple Method for the Early Identification of Gravidas Destined toDevelop Preeclampsia

N.F. Gant, R. Worley and S. Chand

Department of Obstetrics-Gynecology, University of Texas Southwestern Medical

School at Dallas, Dallas, Tex., USA

We have previously reported (J. clin. Invest. 52: 2682, 1973) that young primigravid women, destined to develop pregnancy-induced hypertension, are identifiable 8-12 weeks prior to the onset of clinical signs or symptoms or preeclampsia by the loss of pregnancy-acquired resistance to the pressor effect of angiotensin-II. As a continuation of this study, a clinically useful adjunct has evolved. In a group of young primigravid subjects 28-32 weeks pregnant, the determination of basal diastolic pressure in the left lateral recumbent position, followed immediately by the determination of diastolic pressure in the supine position also, clearly separates two groups. In 14 subjects studied between 28-32 weeks there was a rise in diastolic pressure of $22 \pm 9.2 \mathrm{~mm} \mathrm{Hg}$ $($ mean $\pm \mathrm{SD}$ ) following the assumption of supine position from the lateral. In these subjects subsequent determination of their angiotensin responsiveness showed that each was sensitive to its pressor effect, requiring $4.7 \pm 1.5 \mathrm{ng} \cdot \mathrm{min}-1 \bullet \mathrm{kg}$ ' 1 (mean $\pm \mathrm{SD}$ ) to evoke the pressor response of $20 \mathrm{~mm} \mathrm{Hg}$ rise in diastolic pressure. In the other group of subjects there was no rise or even a decrease in diastolic pressure when turning from the lateral to the supine position. In each of these subjects, angiotensin resistance was subsequently confirmed, the pressor dose required in this group being $15 \pm 2.7 \mathrm{ng} \cdot \mathrm{min} " 1 \cdot \mathrm{kg}$ "1 (mean $\pm \mathrm{SD}$ ) to evoke the pressor response. These data suggest that a clinically useful and simple method exists for the early identification of patients who run very high risks of developing preeclampsia.

4 Effects of Antihypertensive Agents upon Uteroplacental Hemodynamics in ChronicallyHypertensive Pregnant Sheep

Charles R. Brinkman, III, Bahij Nuwayhid and Nicholas S. Assali

Department of Obstetrics-Gynecology, University of California, Los Angeles, Calif., USA

Studies were carried out in a series of chronically-instrumented pregnant sheep in which uteroplacental blood flow (QUA), arterial pressure (AP), and heart rate (HR) were seriallymeasured before and after the production of renal hypertension. The responsiveness and the mechanisms of action of hydralazine, methyldopate and diazv $\Lambda$ :je before and after Scientific Abstracts

9

hypertension were tested. The results are: (1) hydralazine decreased the mean AP by $15 \%$, while the maximal increase in QUA was over $20 \%$ and HR over $50 \%$; (2) the percent change at each interval following the administration of hydralazine was similar between the normotensive and hypertensive animals; (3) when the tachycardia produced by hydralazine is blocked, QUA decreases proportionally to AP; (4) methyldopate reduces the mean AP without significantly 
effecting QUA or HR; (5) diazoxide increases HR while reducing mean AP and QUA. It is concluded: (1) both hydralazine and methyldopate reduce the utero-placental vascular resistance but, because of its positive inotropic and chronotropic effect on the heart, a greater reduction is seen with hydralazine; (2) diazoxide does not appear to have a specific effect upon the uteroplacental vascular resistance; (3) the normotensive and renal hypertensive animals are equally responsive to antihypertensive agents.

5 Immunogenetic Determinants of Placental Size and their Modus operandi

James R. Scott and Alan E. Beer

Departments of Obstetrics-Gynecology and Cell Biology, University Texas Health

Center, Dallas, Tex., USA

Despite the invulnerability of fetuses in utero to a state of specific maternal sensitivity directed against their alien histocompatibility, antigens, it has been suggested that parameters which exert a significant influence on placental weight and extent of trophoblastic invasion are the genetic disparity between the embryo and its mother, and the immunologic status of the mother with regard to the foreign antigens of her fetus. To explore these ideas and to elucidate their basis, groups of inbred rats, mice, and hamsters of similar age, weight, nutritional and endocrinologic status, time-mated, and gestating first litters of the same size, were studied to eliminate nonimmunologic factors. Females were mated with males of their own strain or with males differing at the major or minor histocompatibility loci, and at mating were either untreated, sensitized, genetically tolerant, or had been rendered immuno-logically tolerant with respect to the antigens of the conceptus. Subgroups were treated throughout pregnancy with passive isoantibody directed against alien histocompatibility gene products of their fetuses. Placentas, fetuses, spleen, and para-aortic lymph nodes were individually weighed and examined histologically at a fixed time postconception. Lymphocyte counts from the nodes furnished an index of the level of maternal immunologic response to alien fetuses. It has been found: (a) the greater the immunogenetic disparity between mother and fetus, the greater are the placental weights, draining lymph node weights and cell populations of these nodes, and (b) manipulations of the specific maternal humoral and cellular immune responses exert a significant influence on these parameters as well as upon the extent of trophoblastic proliferation and invasion. 6 Active Immunization to 17/3-Estradiol and its Effects upon the Reproductive Cycle of the Rhesus Monkey

M. Ferin, I. Dyrenfurth, M. Warren and R.L. Vande Wiele

Department of Obstetrics and Gynecology and International Institute for the Study of Human Reproduction, Columbia University, College of Physicians and Surgeons, New York, N.Y., USA Abstract withheld at request of the authors.

Society for Gynecologic Investigation

10

7 Carbon Dioxide and the Long-term Regulation of Fetal Cardiac Output Lawrence D. Londo and Gordon G. Power

Departments of Physiology and Obstetrics-Gynecology, School of Medicine, Loma Linda University, Loma Linda, CA 92354, USA

The fetal cardiac output increases many hundred-fold during the course of gestation. In this theoretical analysis we propose a hypothesis to link icreasing fetal cardiac output to increasing CO., production. We use a systems analysis approach to interrelate the following sequential events: $\uparrow$ fetal 02 consumption, $\uparrow \mathrm{C} 02$ production and $\uparrow$ venous $\mathrm{C} 02$ content; $\uparrow$ fetal total osmotic pressure; $\uparrow$ rate of maternal to fetal water movement across the placenta; $\uparrow$ fetal blood volume, $\dagger$ 
mean systemic pressure; $\uparrow$ cardiac output; $\uparrow$ tissue blood flow; $\downarrow$ veno-arterial C02 content difference; and hence restored venous $\mathrm{C} 02$ content. The proposed hypothesis draws together a number of established mechanisms and relates them to the long-term control of fetal cardiac output. These include Starling's law of capillary water exchange under osmotic and hydrostatic pressure gradients; a large water permeability in the placenta, the sensitive dependence of cardiac output on circulating blood volume and mean systemic pressure, and the relation of total osmotic pressure to $\mathrm{C} 02$ levels in the blood. We have experimental evidence that fetal placental blood $\mathrm{C} 02$ levels, hence total osmotic pressure, affects transplacental water movement. Evidence for most of the other individual processes, such as the relation of total blood osmotic pressure to $\mathrm{C} 02$ levels has been established. The significance of the theory is that it offers for the first time, we believe, a chemomechanical explanation of the increase in blood flow to meet the metabolic demands of growing tissue in the developing fetus.

(Supported in part by USPHS grants HD 03807 and HD 04394.)

8 The Molecular Biophysics of Cervical Mucus Interaction in Solution

Robert M. Nakamura, Masahiko Saga and Val Davajan

Department of Obstetrics-Gynecology, University of Southern California School of

Medicine and the Los Angeles County-USC Medical Center, Los Angeles, Calif., USA

Midcycle cervical mucus is a hydrogel which is made up of high molecular weight

glycoproteins. These glycoprotein molecules constitute approximately $5 \%$ of the total weight of midcycle cervical mucus, the other $95 \%$ being water. The nature of the macro-molecular interaction resulting in the formation of the hydrogel was investigated by removing calcium ion in order to break down the hydrogel into its components. As the purified mucin in the presence of $\mathrm{Ca}++$ results in the viscoelastic properties commonly referred to as Spinnbarkeit, removing the $\mathrm{Ca}++$ eliminated the viscoelasticity. The hydrodynamic properties of the $\mathrm{Ca}++$ free molecule under low shear rate exhibited time dependent intermolecular interaction. Study of purified $\mathrm{Ca}++$ free mucin solutions in various buffers in a concentration of $100 \mu \mathrm{g} / \mathrm{ml}$ showed that viscosity was dependent on ionic strength of the buffers. The viscosity of the mucin solutions markedly increased with time under low shear. With the addition of a 5 X 10 " $3 \mathrm{M} \mathrm{CaCl} 2$ solution to the mucin, a similar time-dependent increase was observed in concentrations of $50 \mu \mathrm{g} / \mathrm{ml}$. These studies show that $\mathrm{Ca}++$ increases the molar volume of the mucin and is responsible for the gelation phenomena. In summary, these studies have shown that ionic interaction is a necessary condition for intermolecular, rather than only intramolecular, interaction of glycoproteins. Scientific Abstracts

11

9 Characterization of Progesterone-Binding Components in Human Endometrium Peter Young and Robert E. Cleary

Department of Obstetrics and Gynecology, Indiana University School of Medicine, Indianapolis, Minn., USA

Abstract withheld at request of the authors.

10 The Use of a Rapid Solid-Phase Radioimmunoassay (RI) Specific for hCG in theDiagnosis and Treatment of Trophoblastic and Non-Trophoblastic Tumors

Donald P. Goldstein, Thomas, S. Kosasa, Arthur T. Skarim and Linda A. Levesque Departments of Obstetrics-Gynecology and Medicine, Harvard Medical School, Boston, Mass., USA A rapid (18 h) solid-phase RIA specific for hCG has been developed using /3-subunit hCG (hCG-B) iodinated 12SI and a potent and specific rabbit anti-hCG-B antiserum coupled to Sephorex R column. Incubation is overnight at room temperature. The within assay coefficient of 
variation $(\mathrm{COV})$ is $3 \%$ and the between assay COV is $10 \%$. The sensitivity is $5 \mathrm{mU} / \mathrm{ml}$. No cross-reaction is noted with $\mathrm{hLH}, \mathrm{hFSH}$, and hTSH.

Serum hCG levels have been monitored in 25 male and female patients with gestational and nongestational trophoblastic tumors before, during, and after surgery and/or chemotherapy. Our studies indicate that more accurate monitoring is achieved with this new method.

Over 200 additional male and female patients with a wide variety of non-trophoblastic malignancies have also been studied and a high percentage with colonic, breast, broncho-genie, ovarian, renal cell carcinoma, and lymphomas appear to secrete hCG ectopically. Serum hCG levels, when present, can be used to monitor treatment also in non-trophoblastic tumor patients. 11 A Role for the Median Eminence (ME) of the Hypothalamus in the Transport ofSubstances from Cerebrospinal Fluid (CSF) to Hypophysial Portal Blood (HPB) John C. Porter, Nira Ben-Jonathan, Renon S. Mical, Robert L. Eskay and Charles Oliver Departments of Obstetrics-Gynecology and Physiology, University of Texas Southwestern Medical School at Dallas, Dallas, Tex., USA It has been hypothesized that the ME may transport releasing hormones from CSF to HPB. To test this hypothesis, $\mathrm{LRH},(3 \mathrm{H}) \mathrm{TRH}, \mathrm{TRH}$, or $(3 \mathrm{H})$ dopamine was injected into a lateral ventricle of rats, and HPB was collected during the next $2 \mathrm{~h}$. LRH was rapidly transported from CSF to HPB. Ten minutes after injection of LRH into the lateral ventricle, LRH was detectable in HPB; and at $20 \mathrm{~min}$, the concentration of LRH in HPB was markedly elevated. If the pituitary gland was intact, transport of LRH from CSF to HPB resulted in stimulation of LH release. However, LH release, once initiated, continued after the LRH levels in HPB were very low, suggesting that LRH bound to anterior pituitary receptors could continue to cause LH release, even though little LRH was being delivered to the gland. $(3 \mathrm{H}) \mathrm{TRH}$, when injected into a lateral ventricle, was also transported rapidly to HPB. If the pituitary gland was intact, the transport of TRH to portal blood caused marked release of TSH. When $(3 \mathrm{H})$ dopamine was injected into the $\mathrm{CSF}$, radioactivity was quickly transported to HPB. However, when HPB was subjected to column chromatography, no free

Society for Gynecologic Investigation

12

$(3 \mathrm{H})$ dopamine was demonstrated in HPB; most of the radioactivity was bound to protein. These results are consistent with the view that neurotransmitters of their metabolites, as well as releasing hormones, can be transported by the ME to HPB from CSF, and that this transport system may be important in controlling hormone release from the anterior pituitary gland.

12 The Postmenopausal Ovary. A Continuing Source of Testosterone in WomenH.L. Judd, W.E. Lucas, D.C. Anderson and S.S.C. Yen

Department of Obstetrics-Gynecology, UCSD, School of Medicine, La Jolla, CA 92037, USA To determine the source of testosterone $(\mathrm{T})$ and androstenedione $(\Delta)$ in women, serum $\mathrm{T}$ and $\Delta$ levels were measured by radioimmunoassay in blood samples obtained before and 6-8 weeks after oophorectomy from five premenopausal and 16 postmenopausal women with endometrial cancer. $T$ and $\Delta$ levels were also measured on base-line samples obtained from six normal postmenopausal women who did not undergo oophorectomy. In the premenopausal patients, the mean \pm SE preoperative $T$ and $\Delta$ levels were $274+15$ and $1,811 \pm 95 \mathrm{pg} / \mathrm{ml}$, respectively, and fell to $118+13 \mathrm{pg} / \mathrm{ml}(\mathrm{T})$ and $911 \pm 97 \mathrm{pg} / \mathrm{ml}(\Delta)$ after oophorectomy. In the postmenopausal patients the preoperative $T(215 \pm 10 \mathrm{pg} / \mathrm{ml})$ and $\Delta(920 \pm 38 \mathrm{pg} / \mathrm{ml})$ levels were significantly lower $(\mathrm{p}<0.001)$ than the concentrations found in the premenopausal women and decreased significantly $(\mathrm{p}<0.001)$ to $99 \pm 10 \mathrm{pg} / \mathrm{ml}(\mathrm{T})$ and $726 \pm 32 \mathrm{pg} / \mathrm{ml}(\Delta)$ following oophorectomy. 
No statistical difference was noted between the preoperative androgen levels in the postmenopausal tumor patients and the base-line $\mathrm{T}(248 \pm 39 \mathrm{pg} / \mathrm{ml})$ and $\Delta(854 \pm 44 \mathrm{pg} / \mathrm{ml})$ concentrations found in the normal postmenopausal subjects. Allowing for possible changes in the metabolic clearance of $\mathrm{T}$, these data suggest that the postmenopausal ovary continues to make substantial amounts of Tbut no $\Delta$.

To confirm the production of $\mathrm{T}$ by the postmenopausal ovary the peripheral and ovarian vein $\mathrm{T}$ levels were measured in five postmenopausal women undergoing bilateral oophorectomy. A marked step-up of $\mathrm{T}$ concentration was noted in the ovarian veins of all five subjects.

13 Reproduction in Women with Sickle Cell Disease Vigorously Transfused with NormalDonor RBC

G. Gary Cunningham, Jack A. Pritchard and Daniel E. Scott

Department of Obstetrics-Gynecology, University of Texas Southwestern Medical

School at Dallas, Dallas, Tex., USA

Reproduction in women with sickle hemoglobinopathies is fraught with severe maternal and perinatal morbidity and mortality. Theoretically, the administration of donor red cells that contain only hemoglobin A, to reduce both the production and the concentration of circulating abnormal hemoglobin, as well as to establish a hemoglobin concentration comparable to that of normal pregnancy, should prove beneficial.

A protocol has been established to maintain the concentration of abnormal hemoglobin below 50 $\%$ and the hematocrit at $32-40 \%$ starting in the first half of pregnancy. This has required as many as 15 units of donor red cells.

The laboratory procedures to monitor the transfusion therapy and the effects on pregnancy include the following: $51 \mathrm{Cr}$ RBC for hemoglobin mass, blood volume, and red

Scientific Abstracts

13

cell survival; quantitative starch block electrophoresis for hemoglobin fractions; serial evaluation of reticulocytes, leukocytes, and platelets; histochemical evaluation of storage iron in aspirates of marrow, and serial fetal sonographic measurements.

Seven patients have been so treated to date: one aborted, two have delivered, and four will deliver soon. Except for the abortion, the pregnancies, symptom-wise, have been remarkably benign. Nonetheless, serial laboratory studies in one patient with SS disease, who has delivered, disclosed late in pregnancy significant destruction, and/or sequestration of endogenously produced SS red cells.

The health status, emotional as well as physical, of the mothers after delivery, remains a concern, because, as the level of abnormal hemoglobins assume their pretreatment values, episodes of debility will probably recur.

14 Renal Bicarbonate (HC03-) Handling in Pregnancy

Victoria S. Lim, Adrian I. Katz and Marshall D. Lindheimer

Departments of Medicine and Obstetrics-Gynecology, University of Chicago, Chicago,

111., USA

Plasma HC03 decreases during normal pregnancy. The decreased renal reclamation of HC03" is believed to represent an adaptive response to respiratory alkalosis. However, increases in extracellular volume and circulating parathyroid hormone (which also increases in pregnancy) might affect the kidney similarly. Sequential NH4C1 loading and HC03- titration studies were performed in five third-trimester women. Base-line arterial $\mathrm{pH}, \mathrm{pC02}$, and $\mathrm{HCO} 3$ " averaged 7.44, $28 \mathrm{~mm} \mathrm{Hg}$ and $19 \mathrm{mEq} / \mathrm{L}$, respectively. Mean tubular reabsorption of P04 was $93 \%$. 
Urinary $\mathrm{pH}$ decreased from 6.1 to 5.5 after $\mathrm{NH} 4 \mathrm{C} 1$, and as noted by others, ammonia and titratable acid excretion increased appropriately. With 5-percent $\mathrm{NaHC03}$ infusion at a rate of 2 $\mathrm{ml} / \mathrm{min}$ (to avoid volume expansion), a urinary threshold for HC03- appeared at a mean plasma $\mathrm{HC} 03$ " of $19.7 \mathrm{mEq} / \mathrm{L}$. However, as plasma HC03" increased progressively there was no evidence of exaggerated splay, and no tubular maximum for $\mathrm{HC} 03$ " was detected with plasma $\mathrm{HC}(\mathrm{V}$ levels as high as $31 \mathrm{mEq} / \mathrm{L}$. During HC03" administration, urinary pC02 increased from 35 to $67 \mathrm{~mm} \mathrm{Hg}$ consistent with a normal distal H + secretory ability. Additionally, metabolic balance studies were performed in two subjects. Blood $\mathrm{pH}$ increased when they changed from a high to a low sodium diet. Conclusions: compensation for respiratory alkalosis appears the primary determinant of urinary $\mathrm{HC} 03$ " wasting in pregnancy, since there was no evidence of exaggerated splay (volume expansion) or decreased P04 reabsorption (expansion or $\dagger$ parahormone). Dietary $\mathrm{Na}+$ restriction enhances $\mathrm{HC} 03$ " reabsorption, thus aggravating the alkalosis.

15 Time Course of Changes in Prostaglandins F and E in Rabbit Ovarian Tissues during Ovulation

Norman S. T. Yang and William J. LeMaire

Department of Obstetrics and Gynecology and the Endocrine Laboratory, University of Miami, Miami, Fla. USA

Abstract withheld by request of the authors.

Society for Gynecologic Investigation

14

16 The Development of a Mathematical Model of DHEA to Estrogen Conversion Dynamics in the Near-Term Pregnant Woman

David A Nagey, Marcos J. Pupkin, Jarlath MacKenna, David W. Schomberg and Carlyle Crenshaw, jr.

Duke University Medical Center, Duke Hospital, Department of Obstetrics and Gyne-cology, Durham

A mathematical model has been developed to study the dynamics of dehydroepiandro-sterone (DHEA) to estrogen conversion to aid in the assessment of fetoplacental unit function, and to further the understanding of the physiology of the fetoplacental unit. The lumped model developed assumes: (1) linearity of DHEA and estrogen conversion and clearance; (2) one pool per hormone; (3) placental transparency to DHEA and estrogen, and (4) a negligible circulation time. The linearity and transparency assumptions are being verified by independent model experiments in the sheep, the assumption of one pool per hormone is being assessed by the goodness-of-fit of the present second-order model and the assumption of negligible circulation time is a tautology due to the sampling intervals used.

The model has been applied to estrogen response data in eight patients thus far, including one normal and seven high-risk obstetric patients. This clinical data is presented in another abstract (Pupkin et al, abstract No. 75). Preliminary indications are that the use of the mathematical model will be clinically useful. At present there is a good correlation between the outcome of the pregnancy and the four model parameters: DHEA clearance rate, DHEA conversion rate, estrogen clearance rate, and base-line estrogen concentration.

17 Maternal and Fetal Plasma Renin Activity during Ovine Pregnancy

Gary K. Oakes, Alan R. Fleischman, Kevin J. Catt, Michael F. Epstein and Ronald

A. Chez

Pregnancy Res. Br., and Sect, in Hormonal Reg., NICHD, NIH, Bethesda, Md., USA 
Plasma renin activity (PRA) was determined in pregnant and nonpregnant Dorset sheep by radioimmunoassay of angiotensin-I generated during incubation of plasma at $\mathrm{pH} 7$ for $3 \mathrm{~h}$ at 37 ${ }^{\circ} \mathrm{C}$. In 15 nonpregnant ewes, the mean ( \pm SD) PRA was $0.4 \pm 0.26 \mathrm{ng} / \mathrm{ml} / \mathrm{h}$. Biweekly maternal plasma samples were obtained from 50 days to term (145 \pm 5 days), and up to 6 weeks postpartum. Maternal PRA rose progressively with levels consistently above $0.7 \mathrm{ng} / \mathrm{ml} / \mathrm{h}$ in late gestation. Mean PRA values were highest at term $(1.9 \mathrm{ng} / \mathrm{ml} / \mathrm{h})$ and moderate variability was seen in the postpartum period with frequent elevations $>4 \mathrm{ng} / \mathrm{ml} / \mathrm{h}$.

In 16 pregnancies, fetal hindlimb dorsal pedal and maternal saphenous vessels were catheterized at 120-125 days. Maternal PRA ranged from 1-4 $\mathrm{ng} / \mathrm{ml} / \mathrm{h}$ with a F:M ratio $>1$. Intravenous injections of furosemide $(25 \mathrm{mg})$ to five ewes was followed by a prompt increase in maternal PRA to a peak of 3 times the basal value after $30 \mathrm{~min}$ with a return to near base-line values at $120 \mathrm{~min}$. There was no consistent change in fetal PRA.

In three other animals, furosemide ( 3 or $6 \mathrm{mg}$ ) was injected i.v. into the fetus. There was a significant rise in PRA in two fetuses and a slight rise above the high base-line value in the third. The maternal PRA did not change.

In summary, maternal PRA values, during late gestation and in the postpartum period, are elevated relative to nonpregnant levels. Fetal PRA is higher than that of the mother.

Administration of furosemide to chronically catheterized nonstressed mothers results in a reproducible increase in maternal PRA and a variable fetal PRA response. Similarly, direct i.v. injection of furosemide to the fetus resulted in a rise in fetal PRA but no change in maternal PRA.

Scientific Abstracts

15

18 Detailed Time-Course of Ovum Transport through Rabbit Oviducts

CarlJ. Pauerstein, Barrie Hodgson and Vicki Anderson

Department of Obstetrics-Gynecology, University of Texas Health Science Center at San Antonio, San Antonio, Tex., USA

Experiments were designed to establish the detailed time-course of ovum transport through the rabbit oviduct, as well as the site of action of agents that delay (estrogen) and accelerate (progesterone) egg transport. Whole oviducts were cleared in benzyl benzoate, and the eggs located in situ. Histologic sections were then cut distal and proximal to each egg or egg cluster, in order to precisely locate the eggs anatomically (isthmus, ampulla or ampullary-isthmic junction). The microscopic anatomy was then correlated with the percent of the distance from the fimbria to the uterotubal junction traversed by the ova. The pause of ova at the ampullary-isthmic junction seen in the controls was exaggerated and prolonged by estrogen. Progesterone, in contrast, seemed to exert its influence in the proximal isthmus. Ova were never found in the 10 $\%$ of the oviduct closest to the uterotubal junction.

19 Effects of Oviductal Denervation on Ovum Transport in the Rabbit

Barrie J. Hodgson, Benjamin Fremming and Carl J. Pauerstein

Departments of Obstetrics-Gynecology and Lab An. Medicine, the University of Texas

Health Science Center at San Antonio, Chicago, Tex., USA

Previous work has suggested that ovum transport is regulated by the sympathetic innervation and adrenoceptors of the oviductal isthmus, which, in turn, are controlled by hormones. Estrogeninduced delay in ovum transport is partially antagonized by $\alpha$-adreno-ceptor blockade. The present experiments were designed to examine the effects of functional sympathectomy on the rate of ovum transport through the rabbit oviduct. Oviducts were depleted of endogenous 
sympathetic neurotransmitter by either surgical denervation, or intraluminal infusion of 6-OH dopamine or systemic administration of reserpine. Functional denervation was confirmed by histochemical examination of the oviducts. These procedures failed to disrupt normal transport rates of ova as indicated by oviductal ovum recovery rates at 24,48 and $72 \mathrm{~h}$ following HCG injection. However, estrogen-induced 'tube-locking' of ova and progesterone-induced acceleration of ovum transport were antagonized by depletion of neurotransmitter from the intrinsic adrenergic nerves of the oviduct. These data suggest that the effects of sex steroids on ovum transport are partially mediated through adrenergic processes.

20 Hormonal Antagonisms in the Regulation of Myometrial Calcium Transport

Mary E. Carsten

Department of Obstetrics-Gynecology, University of California, School of Medicine, Los Angeles, Calif., USA

It is known that oxytocin and some prostaglandins (PG) stimulate uterine contraction while progesterone inhibits uterine activity. The mechanisms of these actions are poorly understood. The requirement for calcium in uterine contraction has prompted us to investigate possible hormonal influences on the calcium transport system.

We have studied effects of progesterone, oxytocin and PGFja, singly and in combinations, on subcellular preparations originating largely from the sarcopiasmic reticulum of bovine and human myometrium. Progesterone $(50 \mu \mathrm{g} / \mathrm{ml})$ caused a statistically significant increase in ATPdependent calcium binding (26\%), while PGF2 $\alpha(100 \mu \mathrm{g} / \mathrm{ml})$ caused a

Society for Gynecologic Investigation

16

decrease in calcium binding ( $45 \%$ ). In the presence of both PGF2 $\alpha$ and progesterone, ATPdependent calcium binding was inhibited by $21 \%$. Effects of oxytocin resembled those of PGFj $\alpha$ - Incubation of the preparations in the presence of both PGF $2 \alpha$ and oxytocin had a greater inhibitory effect on calcium binding than either PGF $2 \alpha$ or oxytocin alone exerted. The data are compatible with calcium binding in relaxation and inhibition of calcium binding in contraction, events which would lower and raise, respectively, the intracellular free calcium available for myometrial contraction. Our results strongly support the view that the hormonal actions are mediated through regulation of cellular calcium transport. (Supported by NIH.)

21 The Metabolic Clearance Rate (MCR) of Norethindrone and Mestranol Before andAfter Prolonged Treatment with These Drugs

Thomas M. Mills, Robert B. Greenblatt, Ta-Jung Lin, James, O. Ellegood and Virendra B. Mahesh

Department of Endocrinology and Center for Population Studies, Medical College of Georgia, Augusta, Ga., USA

The effect of prolonged administration of norethindrone (NOR) and mestranol (MEST) on the MCR and urinary excretion rates of these drugs has been investigated. The MCR was determined by the single injection method; subjects received an intravenous injection of either 3H MEST or $3 \mathrm{H}$ NOR $(5.5 \mu \mathrm{Ci})$ and ten blood samples were collected from $3 \mathrm{~min}$ to $24 \mathrm{~h}$ after injection. The $3 \mathrm{H}$ NOR or $3 \mathrm{H}$ MEST in each plasma sample was quantitated following TLC purification; the total $3 \mathrm{H}$ content of each sample was also measured. Daily urine samples were collected for 5 days following injection. After these initial determinations of MCR and excretion rates, subjects were placed on six monthly cycles of either NOR $(2.5 \mathrm{mg} /$ day $)$ or MEST $(0.08 \mathrm{mg} /$ day $)$ and then rehospitalized for repeat determinations of the MCR and excretion rates. In the eight NOR subjects, the initial MCR was $598 \pm 651 /$ day $(x \pm S E)$ and was significantly elevated to $775 \pm$ 
1031 day after six monthly cycles of the drug ( $p<0.05$ by paired variable t-test). In seven MEST subjects, the initial MCR was 1,288 \pm 1401 /day and the final MCR was 1,248 \pm 167 $1 /$ day $(\mathrm{p}>0.4)$. About $60 \%$ of the $3 \mathrm{H}$ injected as NOR and approximately $30 \%$ of the $3 \mathrm{H}$ administered as MEST was excreted in the 5 days of urine collection. Six cycles of drug treatment did not significantly alter either the daily or the total excretion rates of either drug $(\mathrm{p}>$ 0.01 ) While both NOR and MEST were cleared rapidly, metabolites (represented by the total $3 \mathrm{H})$ persisted in the plasma at elevated levels for more than 5 days after injection of the $3 \mathrm{H} \mathrm{drug.}$ The identity and biological activity of these compounds is now being investigated.

22 Relationship of Oligomenorrhea and Obesity to the Hyperandrogenism of HirsuteWomen A.H. Hosseinian, M.H. Kim and R.L. Rosenfield

University of Chicago, Department of Obstetrics-Gynecology and Pediatrics, Chicago, 111., USA

Hirsutism, oligomenorrhea and obesity are common accompaniments of hyperandro-genic states, e.g. polycystic ovary syndrome. We have explored the extent to which the reported correlation between hirsutism and hyperandrogenism is related to these associated clinical features. High levels of total testosterone (TTe), indexes of free testosterone (FTel) and free 17/3hydroxysteroid androgens (FHSI) in plasma, and low levels of testosterone binding globulin (TeBG) capacity were considered indicative of hyperandrogenism. Mean results are:

Scientific Abstracts

17

Disorder (number) TTe, FTel FHSI TeBG, $\mathrm{ng} \% \quad \mu \mathrm{g} / \mathrm{L}$

Normal female (24)

Eumenorrhea + obesity (3)

Oligomenorrhea (11)

Oligomenorrhea + obesity (11)

Oligomenorrhea + hirsutism (mild) (14)

Oligomenorrhea + hirsutism (mild) + obesity (4)

Eumenorrhea + hirsutism ( $>$ mod.) $(6)$

Oligomenorrhea + hirsutism $(>\bmod$.) $(7)$

Oligomenorrhea + hirsutism ( $>$ mod.) + obesity (8) $68.3 \quad 31.5 \quad 143.8 \quad 8.0$

Mild hirsutism, oligomenorrhea or obesity alone are not associated with abnormal free androgens or TeBG. However, hyperandrogenism is present in the nonhirsute with oligomenorrhea plus obesity. The relationship between hirsutism and hyperandrogenism is closer when oligomenorrhea and/or obesity are present. The 'threshold' at which hirsutism appears in response to androgens can be raised by obesity.

23 Blood Flow and Hormone Secretion in the Preovulatory Rabbit L. Plasco, C.H. Wu, G.L. Flickinger and G. Mikhail

University of Pennsylvania School of Medicine, Department of Obstetrics-Gynecology, Philadelphia, Pa., USA

Radiolabelled microspheres were used to study hourly changes in cardiac output and blood flow distribution to the genital organs in a 10-hour period following HCG administration to rabbits. Throughout this period the ovarian blood flow was higher $(1.15 \pm 30 \mathrm{ml} / \mathrm{min} /$ organ $)$ than in the estrous animal $(0.17 \pm 0.02)$. A maximal value $(3.0 \pm 0.6)$ was obtained $3-4 \mathrm{~h}$ after HCG and was associated with a very high perfusion rate $(12.4 \pm 3.0 \mathrm{ml} / \mathrm{min} / \mathrm{g})$. In this same time interval, cardiac output reached a peak level of $780 \pm 133 \mathrm{ml} / \mathrm{min}$ and the fraction of cardiac output 
perfusing the ovary at that time was highest $(0.43 \pm 0.9 \%)$. This period of maximal ovarian blood flow was associated with the highest secretion rate of progesterone $(10.62 \pm 2 \mu \mathrm{g} / \mathrm{h} /$ ovary $)$, estradiol (73 $\pm 2 \mathrm{ng} / \mathrm{h} /$ ovary) and estrone (103 $\pm 40 \mathrm{ng} / \mathrm{h} /$ ovary). Blood flow to other genital organs, expressed as percent of cardiac output, remained fairly constant throughout the preovulatory period with a mean value of $0.19 \pm 0.02 \%$ for fallopian tube, $0.40 \pm 0.06 \%$ for uterine horn, $0.17 \pm 0.03 \%$ for cervix, and $0.21 \pm 0.03 \%$ for the vagina.

The significant changes in ovarian blood flow and hormonal secretion, following HCG administration, may play an essential role in the mechanism leading to ovulation.

24 Diurnal and Episodic Changes in the Plasma Free Testosterone Level in Females

Robert L. Rosenfield and James Helke

Biomedical Center for Population Research and Department of Pediatrics, University

of Chicago, Chicago, 111., USA

The possibility that diurnal or episodic variation of the plasma testosterone level might occur in women has been explored. Diurnal variation was examined by sampling blood at $2-4 \mathrm{~h}$ intervals in five normal women at various phases of the menstrual cycle. Episodic

Society for Gynecologic Investigation

18

variation was examined by sampling every $5-15 \min$ for 9.5 woman-hours. Plasma testosterone was measured by a radioimmunoassay method, the precision of which was $9 \%$. Indexes of the concentration of free testosterone and of the free fraction of total plasma androgens (" $17 \mathrm{j} 3$ hydroxysteroids') were determined by competitive protein binding methods.

The average fluctuation of plasma testosterone about the 24 -hour mean was $14 \%$. A small degree of diurnal variation in total and free plasma testosterone levels could be discerned: 8 p.m. levels averaged $80 \%$ of those at 8 a.m. This rhythm was similar to, but less marked than, the known diurnal fluctuation in total 17/3-hydroxysteroids. Superimposed upon this cortisol-like rhythm was a small random fluctuation in testosterone levels. These latter changes were not related to plasma cortisol levels and are presumed to result from episodic ovarian secretion. In spite of the diurnal rhythm and episodic changes, the concentration of plasma free androgens consistently fell within the narrow range previously found to be normal during the menstrual cycle. Testosterone peaks never ranged more than $40 \%$ above the 24 -hour mean. These data demonstrate that an accurate, single, elevated free plasma testosterone level is indicative of hyperandrogenism.

(Supported by USPHS grants RR-305, HD-7052, HD-07110 and HD-06308.)

25 Immunologic Consequences to Neonates of Milk-Borne LeucocytesAlan E. Beer, Judith

R. Head and R.E. Billingham

Department of Cell Biology, University of Texas Health Science Center, Dallas, Tex., USA

The immunologic role of the mammary gland is usually regarded as being entirely beneficient. It transfers via its exosecretion a quota of ready-made antibodies from the maternal serum to the GI tract of the immunologically naive infant where it fulfills a local exogenous immunoprotective function. In certain species it deputizes for the fetal membranes which are incapable of transmitting antibodies to the fetus in utero. Apart from this beneficial role, in some species colostrum and milk present potential threats to the well-being of the recipients by virtue of their containing: (a) antibodies which can initiate hemo-lytic disease of the newborn: (b) proteins which are potent sources of harmful allergic reactions possibly including the sudden infant death syndrome in man, and (c) leucocytes and macrophages in numbers equal to those in peripheral blood. Experiments were conducted in inbred rats to investigate the immunologic consequences 
of this natural maternal to neonatal transfer to milk-borne leucocytes. It has been found that: (a) postpartum sensi-tization of mothers with grafts of their infant's skin causes the development of exfoliative skin lesions of the sucklings which reflects the existence of skin specific antigens; (b) foster nursing of genetically appropriate neonates by normal mothers can result in impairment or heightening of the infant's reactivity to alien maternal tissue antigens - tolerance or sensitivity, or the development of graft-versus-host disease. These findings indicate that in the species studied, milk-borne lymphocytes are absorbed in a viable condition into the tissues of the neonate.

26 Diurnal Variations in Uterine Activity and Catecholamines

Guy M. Harbert, jr. and Frederick P. Zuspan

University of Virginia School of Medicine, Department of Obstetrics and Gynecology, Charlottesville and University of Chicago, Department of Obstetrics and Gynecology, Chicago, 111., USA

Abstract withheld by request of the authors.

Scientific Abstracts

19

27 Plasma Sex Steroid Levels and the in vitro Response of the Isthmic Human Portion ofOviduct to Catecholamines

A.H. Moawad and Moon Kim

University of Chicago, Department of Obstetrics-Gynecology, Chicago, 111., USA

Our previous data showed that the response of the human isthmus musculature, to

catecholamines, differ in various phases of the menstrual cycle. Although tissue from subjects in the secretory and menstrual phases responded by inhibition, those in the prolifera-tive phase had a mixed response. Therefore, it was felt that precise determination of sex steroid levels is necessary.

This report deals with further correlation of the predominance of adrenoreceptors in this tissue with plasma estrone, estradiol and progesterone. Circular segments from the isthmus of 26 normal subjects with various hormonal background were subjected to trans-mural field stimulation recording isometric contractions.

Four groups were identified, their response to field stimulation was as follows: (1)good estrogen and insignificant progesterone respond by increase in the contractility area and the tone; (2) low estrogen and insignificant progesterone respond by a decrease in the area and tone; (3) good estrogen and significant progesterone respond by a decrease in the area and tone, and (4) in pregnancy the response is as number 3 .

Transmural field stimulation was abolished by the use of tetrodotoxin, demonstrating that these responses are due to the endogenous neuratransmitter.

Dose response relationship to epinephrine in these preparations were constructed before and after $\beta$ - or $\alpha$-adrenergic receptors blockade.

Results from these experiments show that $\alpha$-adrenergic receptor activity predominate with the progressive increase in estrogen secretion. The addition of progesterone reverse this phenomenon leading to the rise of (3-adrenergic receptor activity.

28 The Precursor Role of Acetate and Cholesterol for Steroids in the Newborn Baboon

Herman A.J. Schut and Samuel Solomon

Department of Biochemistry and Experimental Medicine, McGill University and University

Clinic, Royal Victoria Hospital, Montreal, Canada

Abstract withheld by request of the authors. 
29 In vitro Studies of Testicular Steroid Metabolism in 170-Reductase DeficiencyFrank Z. Stanczyk, Theodore D. Hall, Wellington L. Paul and Uwe GoebelsmannUniversity of Southern California School of Medicine, Department of Obstetrics-Gynecology, Los Angeles, Calif., USA Steroid metabolism was studied in testicular tissue obtained from a 46-year-old male pseudohermaphrodite with gynecomastia and virilization, attributed to ПØ-hydroxysteroid dehydrogenase deficiency (17-DHD), in order to investigate the mechanism(s) responsible for this patient's highly elevated $4 \Delta$-androstenedione (A) and estrone (E,), but only minimal testosterone (T) and estradiol (E2) secretion. Testes from two testicular feminization patients with normal serum A, T E, and E2 concentrations were used as controls. 14C-labeled pregnenolone $(5 \Delta \mathrm{P}), 17$-hydroxyprogesterone (17-OHP), dehydroepiandrosterone (DHEA), A, $\mathrm{T}$, and $\mathrm{E}$, was incubated with testicular minces and homogenates in Krebs-Ringer phosphate buffer, $\mathrm{pH}=7.4$, with and without the addition of cofactors. Tritiated

Society for Gynecologic Investigation

20

and unlabeled steroids (precursors and principal expected metabolites) were added prior to extraction to facilitate recovery estimates and detection during isolation and identification carried out by paper chromatography and recrystallization to constant specific activity and $3 \mathrm{H}: 14 \mathrm{C}$ ratio. The results obtained with minced tissues indicate that the 17-DHD testes metabolized more $5 \Delta \mathrm{P}$ as well as 17-OHP and produced more A, yet much less T, than the control. Considerably more A was obtained from DHEA in the 17-DHD testes which reduced only minimal quantities of DHEA, A and E,. 17(3-reduction was slightly increased when NADH/NADPH was added. However, when NAD/NADP was added, T was oxidized to A in amounts comparable to the control. The number of plausible explanations for these results was reduced when addition of NADH to homogenates of the 17-DHD testes effected reduction of $A$ to $T$, but addition of NADPH, more effective than NADH in the control, did not result in reduction of A to T. Thus, this patient's lack of testicular T production and resulting male pseudohermaphroditism may be explained by a decrease in 17/3-hydroxy-steroid dehydrogenase affinity for NADPH.

(USPHS grant HD05932 and Ford Foundation grant 690-0650.)

30 Phosphatidic Acid Phosphohydrolase Activity in Human Amniotic Fluid

Juan M. Jimenez, F. Michael Schultz, Paul C. MacDonald and John M. Johnston Departments of Obstetrics-Gynecology and Biochemistry, University of Texas Southwestern Medical School at Dallas, Dallas, Tex., USA

Phosphatidylcholine biosynthesis occurs via several pathways in lung as well as other tissues. Phosphatidic acid is a key intermediate in the various biosynthetic processes. In the reaction sequence, phosphatidic acid is then hydrolyzed via the enzyme phosphatidic acid phosphohydrolase (PAPase) forming the diglyceride intermediate. The diglyceride then acts as an acceptor of phosphorylcholine, the donor being CDP-choline. The specific activity of PAPase in the fetal rabbit lung has been found to increase fourfold from day 23 to adult levels at day 30 . The increase in activity of the enzyme in fetal rabbit lung precedes by approximately $24 \mathrm{~h}$ the reported increase in phosphatidylcholine concentration.

The activity of PAPase has recently been found in human amniotic fluid. The specific activity of the enzyme was markedly increased in the amniotic fluid obtained from term pregnancies. In all cases, thus far examined serially, throughout gestation, the increase in specific activity of PAPase preceded the surge of phosphatidylcholine. The possible relationship of the enzyme specific activity to fetal lung maturation will be discussed.

31 Effect of Exchange Transfusion on Cardiac Tissue Oxygen Unloading of NewbornLambs 
Maria Delivoria-Papadopoulos, C. Richard Park, Juh-Huey Chen, Richard H. Schwarz and Robert E. Forster, II

University of Pennsylvania, School of Medicine, Departments of Physiology, Obstetrics and Gynecology, and Pediatrics, Philadelphia, Pa., USA

Previous studies have shown that in newborn piglets a decrease in whole blood oxygen affinity results in an increased mixed venous p02 and decreased cardiac output for the same oxygen consumption (V02). The present studies were designed to investigate the response of a specific organ, the heart, to an acute shift of the oxyhemoglobin equilibrium curve to the right. Under general anesthesia, polyvinyl catheters were placed chronically in the right ventricle, carotid artery and coronary sinus of newborn lambs by direct visualization during

Scientific Abstracts

21

thoracotomy. Measurements of blood Hb02 saturation, p02, pC02, pH and P50 in all these vessels and total V02 were obtained before, and 3 and $24 \mathrm{~h}$ after transfusion. Arteriovenous oxygen content difference (AVD) and cardiac output were calculated. In the eight animals studied, mean coronary sinus p02 rose from 18 to $31 \mathrm{~mm} \mathrm{Hg}$, mean 02 content decreased from 5.8 to $3.5 \mathrm{ml} \mathrm{O} 2 / 100 \mathrm{ml}$ of blood, AVD across the heart increased from 7.7 to $8.8 \mathrm{ml} / 100 \mathrm{ml}$ of blood while the total cardiac output decreased from 260 to $170 \mathrm{ml} / \mathrm{min} \mathrm{X} \mathrm{kg}$. These data indicate that decreasing blood 02 affinity resulted in an increase in coronary sinus p 02 and AVD of the heart as well as in a decrease in cardiac output. These results suggest an improvement in myocardial tissue oxygenation.

(Supported in part by USPHS 1-R01-HD 07135-02 and USPHS 2-R01-HD 01860-06A2.)

32 Steroid Receptors in Human Fetal Membranes

B.E. Schwarz, P. Vanatta, P.K. SiíteriandP.C. MacDonald

Departments of Obstetrics-Gynecology, University of Texas Southwestern Medical

School at Dallas, Dallas, Tex., USA

Recent findings in our laboratories that fetal membranes are a site of considerable and varied hormone production and metabolic capability suggested that fetal membranes may be a target tissue for certain steroid hormones. Fetal membranes were obtained immediately after vaginal delivery or at cesarean section from women delivering at term. Analyses of binding of $3 \mathrm{H}-$ progesterone and $3 \mathrm{H}$-cortisol were performed on sucrose density gradients containing internal standards of 14C-acetylated human serum albumin which permitted accurate assignment of S values. Analyses of binding affinities were performed by absorption of unbound steroid onto activated charcoal. A protein 'receptor' which binds cortisol, cortisone, and progesterone can be demonstrated in the cytosol of human fetal membranes but not in cytosol of non-target tissue such as maternal peritoneum. The hormone-'receptor' complex sediments at $4 \mathrm{~S}$ in both low salt and high salt gradients and is apparently the same whether obtained from whole tissue or broken cell experiments. Exposure of the progester-one-'receptor' complex to a pellet containing predominantly cytoplasmic organelles (mitochondria, lysosomes and microsomes) for $15 \mathrm{~min}$ at $37 \mathrm{CC}$ resulted in the nearly complete removal of progesterone from the cytosol and association of the progesterone with the cytoplasmic organelles. However, the progesterone could not be recovered from the pellet by extraction with $0.4 \mathrm{M} \mathrm{KC1}$.

33 Continuous Ultrasonic Determination of Cervical Dilatation during Labor

M.R. Neuman and I. Zador

Perinatal Clinical Research Center, Cleveland Metropolitan General Hospital, Case

Western Reserve University, Cleveland, Ohio, USA 
Abstract withheld by request of the authors.

34 The Effect of Weight Loss on Pituitary Response to LH-RH in Women with

SecondaryAmenorrhea

Michelle P. Warren, Ralph Jewelewicz, Inga Dyrenfurth, Roy Ans, Suhail Khalaf and Raymond

L. Vande Wiele

Department of Obstetrics and Gynecology and Medicine, George Washington University School of Medicine, Washington, D.C., USA

Abstract withheld by request of the authors.

Society for Gynecologic Investigation

22

35 Amniotic Fluid 32 -Microglobulin Concentration. An Index of Gestational Age

Philip W. Hall, III and Jacques F. Roux

Department of Medicine and Reproductive Biology, Case Western Reserve University,

School of Medicine, Cleveland Metro General Hospital, Cleveland, Ohio, USA

The renal tubule actively metabolizes many low molecular weight proteins, i.e. insulin, IgG light chains, lysozyme, and $\beta 2$-microglobulin. Their molecular size is small enough to permit relatively free passage through the normal glomerular basement membrane. With primary tubular disorders, tubular metabolism of these proteins is diminished and, as a consequence, their urinary excretion is increased. Recent studies from this laboratory indicate a progressive increase in tubular uptake of one of these proteins, i.e. /32-microglobulin, during the early oliguric phase of renal function following cadaveric renal transplantation. The origin and function of $\beta 2-$ microglobulin are unknown. If fetal production precedes tubular metabolism of this protein it should accumulate in amniotic fluid during fetal development until the renal tubule matures. B2 -Microglobulin concentrations were measured in amniotic fluid obtained from 20 women at various stages of gestation. The concentrations averaged $6.3 \mu \mathrm{g} / \mathrm{ml}$ (range 5-10) between the tenth and thirty-sixth weeks of gestation. All samples obtained after 36 weeks had B2-

microglobulin concentrations varying between 0.2 and $1.3 \mu \mathrm{g} / \mathrm{ml}$ (average 0.87 ). This sudden decrease in amniotic fluid concentration suggests that a major fetal pathway for metabolism of this protein becomes functional late in the course of gestation. From what is known of 32 microglobulin metabolism, this most likely relates to the degree of maturation of renal tubular epithelium. These data indicate that this test should have considerable value in determination of fetal age.

36 Control of Uterine Ribosome Activity by Estrogen-Dependent Factors in the Uterine Cytosol Kenneth L. Barker and Sandra M. Whelly University of Nebraska College of Medicine, Departments of Obstetrics-Gynecology and Biochemistry, Omaha, Nebr., USA

One of the early effects of estradiol (E2) on the ovariectomized mature rat uterus is a transient increase at $1 \mathrm{~h}$ in the rate of peptide elongation by uterine ribosomes - Whelly and Barker, Fed. Proc. 32: 241 (1972) (abstr.) and Biochemistry (in press, 1974). This response is independent from the E2 effect on RNA synthesis. Further evaluation of this response indicates that uterine ribosomes isolated from control rats are in an inhibited state and that the inhibition is reversed by E2. The protein synthesis capacity of isolated uterine ribosomes from control or $1 \mathrm{~h} \mathrm{E} 2$-treated ovariectomized mature rats was determined by measuring the rate of incorporation of $14 \mathrm{C}$ leucine into protein in a cell-free protein synthesis system. Washing isolated uterine ribosomes from control and E2-treated rats with $0.5 \mathrm{M} \mathrm{KCl}$ results in activation of control but not E2treated ribosomes. Preincubation of isolated uterine ribosomes, but not liver ribosomes, with 
uterine cytosol from control, but not E2-treated, rats at $25^{\circ} \mathrm{C}$ for 30 -min results in a $40-60$ percent inhibition in their subsequent capacity to support protein synthesis. Addition of 17/3estradiol, but not $\prod \alpha$-estradiol, progesterone or testosterone, during preincubation, reverses the inhibitory effect of uterine cytosol. The early activation of uterine ribosomes by E2 appears to result from reversal of the effects of a uterine specific inhibitor of ribosome function by the activated cytosol estrogen-receptor.

Scientific Abstracts

23

The activation of preexisting ribosomes would facilitate the utilization of newly synthesized messenger RNA prior to the synthesis of new ribosomes. (Supported by NIH grants HD-02851 and HD-38656.)

37 Molecular Functions of Estradiol in the Association of Uterine Receptor withChromatin Marvin L. Chatkoff, JoAnnel L. Julian and Robert J. Young Departments of Obstetrics-Gynecology and Lab. A. Medicine, University of Texas Health Science Center, Medical School, San Antonio, Tex., USA Estradiol complexed with receptor in the nuclei of uterine tissue stimulates prolifera-tive processes after binding to a chromatin fraction. Experiments were designed to test the suggestion that estradiol is a necessary component in the binding process. Uterine cytosol extracts from castrated rabbits containing estradiol receptor were incubated with $3 \mathrm{H}$-estradiol; the free estradiol was removed and a series of concentrations of the solution were incubated in vitro with 1 week castrate uterine chromatin. Chromatin bound estradiol-receptor complex was determined as a function of the receptor concentration, the incubation temperature, and the reaction time. Forward and backward reaction velocities, affinities, and the number of available chromating binding sites were determined. Competition between estradiol-receptor complex and estradiolfree receptor for chromatin sites was also investigated. Evidence is presented that estradiol is neither necessary for binding of receptor to chromatin nor does it significantly influence equilibrium binding parameters. The affinity of approx. $1010 \mathrm{M}$ is shown to correlate with an estimated association time of less than $2 \mathrm{~min}$ at $37^{\circ} \mathrm{C}$. The number of active genomes in a target cell was estimated from the binding sites. It is also demonstrated that estradiol binds to receptor, previously bound to chromatin. These results suggest that the receptor may have two disjoint binding sites; one for estradiol and another for chromatin binding.

38 A Specific Progesterone Receptor of Human Myometrial Cytosol

D. V. Illingworth, G.L. Flickinger, C.H. Wu and G. Mikhail

University of Pennsylvania School of Medicine, Department of Obstetrics-Gynecology, Philadelphia, Pa., USA

A specific progesterone $(\mathrm{P})$ receptor, distinct from $\mathrm{CBG}$, has been identified in human myometrial cytosol. Synthetic C21 and C19 progestogens and 5a-pregnanedione had almost equal affinity for the receptor as $\mathrm{P}$, while $20 \alpha-\mathrm{OH}-\mathrm{P}, 17 \alpha-\mathrm{OH}-\mathrm{P}$, cortisol and corticosterone had much lower affinity. The sedimentation coefficient, measured by sucrose density cen-trifugation, was 4S. Cervical and vaginal tissues from the same patients appeared to lack specific P receptor. Receptor concentrations and affinity constants $(K=1 \mathrm{X} 10-9 \mathrm{M})$ have been measured using a dextran-coated charcoal technique and computer analysis of Scatch-ard plot data. Higher levels were found during the proliferative $(54.0 \pm 8.2 \mathrm{\ddagger M} / \mathrm{mg}$ protein, $\mathrm{n}=15)$ than during the secretory $(34.5 \pm 6.0, \mathrm{n}=16)$ phase of the menstrual cycle, or in the anovulatory patients $(27.8 \pm 6.0, \mathrm{n}=$ 9). Progesterone receptor was not detectable in patients taking oral contraceptives. Estrogen therapy of post-menopausal patients increased receptor concentrations $(47.8 \pm 14.7, \mathrm{n}=4)$ 
compared to untreated peri and postmeno-pausal patients $(15.5 \pm 3.4, \mathrm{n}=7)$. Ovarian hormone secretion seems to be necessary for the maintenance of significant levels of $P$ receptor in the myometrium. The amounts of receptor also seem to be influenced by the hormonal status, being depressed by progesterone and stimulated by estrogen.

Society for Gynecologic Investigation

24

39 Binding Interactions of Progesterone, Corticosterone and Cortisol with Rat

UterineCytosol

Antonio E. Colas and Barbara A. Booth

University of Wisconsin Medical School, Department of Obstetrics and Gynecology and

Endocrine Reproduction, Physiological Program, Madison, Wisc., USA

Abstract withheld by request of the authors.

40 The Effect of Actinomycin-D on Estrogen-Induced Uterine Blood Flow

Robert Resnik, Frederick C. Battaglia, Edgar L. Makowski and Giacomo Meschia University of Colorado Medical Center, Division of Perinatal Medicine, Denver, Colo., USA

The effect of estrogens in increasing uterine blood flow has been described extensively, but the mechanisms involved remain unknown. Actinomycin-D blocks the uterotrophic effect of estradiol-17/3, implying that DNA-dependent RNA synthesis is a prerequisite for uterine growth. Furthermore, it has been shown in our laboratory that cycloheximide, an inhibitor of protein synthesis, blocks the effect of estrogen on uterine blood flow. We have utilized nonpregnant, oophorectomized ewes with uterine arterial catheters and chronically implanted electromagnetic flow probes around both uterine arteries to determine the effect of actinomycin-D on the uterine vasodilatation produced by estradiol-17j3. After an infusion of actinomycin-D $200 \mu \mathrm{g}$ into one uterine artery, the ewe was given estradiol-17)3 $1 \mu \mathrm{g} / \mathrm{kg}$ systematically. Two hours after estrogen administration, when peak blood flows were achieved, $5 \mu \mathrm{Ci} 3 \mathrm{H}$-uridine was infused through each uterine artery. Incorporation of $3 \mathrm{H}$-uridine into RNA was significantly higher in the control horn than in the uterine horn receiving actinomycin-D. The mean inhibition of incorporation in four experiments was $60 \%$. Actinomycin-D had no effect on uterine blood flow; thus it is unlikely that transcrip-tional events are an immediate prerequisite of the uterine blood flow response to estrogens.

41 Placental Membrane Limitation of Fetal Glucose Uptake in Sheep

Michael A. Simmons, M. Douglas Jones, jr., Frederick C. Battaglia, Edgar L. Makowski and Giacomo Meschia

Division of Perinatal Medicine, University of Colorado Medical Center, Denver, Colo., USA

Transplacental diffusion of inert substances has been described in terms of flow limitation (e.g. water, antipyrine) and membrane-diffusion limitation (e.g. $\mathrm{Na}+, \mathrm{C} \Gamma$, urea). Placental clearance measurements have been used to define the degree of flow-limited or membrane-limited transport. This study begins to describe the placental clearance characteristics of a metabolically non-inert substance - glucose. Four ewes with gestations of 95-135 days had catheters placed in a fetal artery, vein, and umbilical vein, and in a maternal artery. Glucose, urea, antipyrine clearances, as well as umbilical blood flow, were measured in each animal on two consecutive days after recovery from surgery. Antipyrine clearances $(100.2 \mathrm{ml} / \mathrm{min} / \mathrm{kg} \pm 6.2 \mathrm{SEM})$ and urea clearances $(28.9 \mathrm{ml} / \mathrm{min} / \mathrm{kg} \pm 1.7 \mathrm{SEM})$ were within the ranges previously described. Glucose clearances $(12.7 \mathrm{ml} / \mathrm{min} / \mathrm{kg} \pm 2.4 \mathrm{SEM})$ were $\sim 50 \%$ less than simultaneously determined urea 
clearances $([\mathrm{C}]$ giucose $\mathrm{ml} / \mathrm{min}=4.12+0.35[\mathrm{C}]$ urea $\mathrm{ml} / \mathrm{min}$ ), thus demonstrating that placental glucose transport is primarily membrane

Scientific Abstracts

25

limited. Calculations based on these clearances show that a twofold increase or decrease in maternal placental blood flow leads to only a $\pm 5 \%$ change in fetal glucose uptake.

42 Intrauterine Fetal Sex Determination by Radioimmunoassay of Amniotic Fluid Testosterone

Harlan R. Giles, Charles D. Lox, M. Wayne Heine and CD. Christian

Department of Obstetrics-Gynecology, University of Arizona College of Medicine,

Tucson, Ariz., USA

Amniotic fluid testosterone levels were measured by radioimmunoassay techniques from 75 term pregnancies and from 32 pregnancies interrupted before 20 weeks' gestation.

Statistically significant differences $(\mathrm{p}<0.05)$ were found between term males $(123 \mathrm{pg} / \mathrm{ml})$ and term females $(63 \mathrm{pg} / \mathrm{ml})$ and between less than 20 -week males $(162 \mathrm{pg} / \mathrm{ml})$ versus less than 20 week females $(54 \mathrm{pg} / \mathrm{ml})$.

However, the levels between term males and less than 20 -week males were not significantly different $(\mathrm{p}<0.05)$ and the hormone levels between term females and less than 20 -week females also were not significantly different.

Utilizing a blind approach study, the sex of 20 of 20 male fetuses less than 20 -weeks of gestation, and 12 of 12 female fetuses less than 20 weeks of gestation, were correctly predicted solely on the basis of amniotic fluid testosterone levels, utilizing a breaking point of $96 \mathrm{pg} / \mathrm{ml}$. The implications for genetic counselling by using this quick methodology for intrauterine sex determinations instead of, or in addition to, karyotypic analyses, are apparent.

43 Oxygen Consumption in Pregnancy

Martin L. Pernoll, James Metcalfe and Thomas L. Schlenker

Departments of Obstetrics-Gynecology and Medicine, University of Oregon Medical

School, Portland, Oreg., USA

Oxygen consumption (V02) of seven normal women was measured at monthly intervals during pregnancy and 2, 6 and 12 weeks postpartum. At each study, measurements were made sitting at rest, during steady-state exercise on a bicycle ergometer (50 watts), and for $10 \mathrm{~min}$ of recovery.

The highly significant increase $(* p<0.01)$ in V02 (exercise) and oxygen debt observed in late pregnancy (compared to $12+$ weeks postpartum in the same individual) suggests that mild sitting exercise costs more in terms of oxygen consumption during late pregnancy than in the nonpregnant state. Part of the increased oxygen cost of exercise during pregnancy is due to increased work of the respiratory muscles associated with hyper-ventilation. In addition, as previously reported, cardiac output increases more during exercise in pregnant women, so that increased myocardial oxygen consumption may also add to the total oxygen cost of exercise. Society for Gynecologic Investigation

26

44 Blood Pressure during Estrogen + Progestin Contraception After Pregnancy-Induced Hypertension

Jack A. Pritchard, Uel D. Crosby, Frances G. Martin and Signe A. Pritchard Department of Obstetrics-Gynecology, University of Texas Southwestern Medical School at Dallas, Dallas, Tex., USA 
Sequentially measured blood pressures (BP) have been analyzed for 150 primiparas 14-24 years of age, who had developed hypertension late in pregnancy and then 2-4 weeks postpartum started estrogen + progestin contraception (OC).

Blood pressure Late pregnancy Months, estrogen + progestin used

maxi- mean $03 \quad 6 \quad 12182430$

mum

Mean systolic $172152 \quad 119118118115115115112$

Mean diastolic $112101 \quad 76747373727370$

Subjects (No.) (150) (150) (150) (150) (128) (105) (76) (46) (27)

Although $84 \%$ are black, diastolic BP are remarkably similar to those reported by Kunin et al.

for white OC non-users, 15-24 years of age - Arch, intern. Med. 72.?: 362 (1969).

Diastolic BP rose to $>90$ in eight of $138(5.8 \%)$ whose BP postpartum before OC was 90 or less. In four of the eight BP, $>90$ persisted after stopping OC; in two of eight it decreased to < 90 and hypertension did not recur when OC was restarted; two were lost for follow-up. Diastolic BP subsequently decreased to $<90$ in all of 12 whose initial diastolic BP was $>90$ yet were given OC.

38 with diastolic $\mathrm{BP}<90$ while using $\mathrm{OC}$ conceived again; hypertension recurred in six.

Conclusions: (1) young women with previous pregnancy-induced hypertension are not unduly prone to develop hypertension while using estrogen + progestin contraception; (2) hypertension induced by $\mathrm{OC}$ and by pregnancy, probably results from different mechanisms.

45 Ultrastructural Basis for Electrical Coupling in Myometrium and Hormonal Effects Thereon R.E. Gar field and E.E. Daniel

The University of Alberta School of Medicine, Department of Pharmacology, Edmonton, Alberta, Canada

Uterine muscle cells initiate action potentials or spikes, and these are coupled cell-to-cell. This coupling appears to be under the control of hormones, as the velocity of spread of action potentials, and the probability of spread, increase with pregnancy. The ultrastructural basis of these phenomena has never been established; but it has been suggested that the differences in the nature of cell-to-cell contacts, especially gap junctions or nexuses, may be involved. We have studied the occurrence of all types of cell-to-cell contacts in longitudinal and circular muscle layers of rat myometrium, in estrogen-dominated, progesterone-dominated, and pregnant conditions. No gap junctions (nexuses), commonly assumed to be low-resistance contacts, were found in either layer under any condition. There were differences in the other types of cell-to-cell contacts found, close apposition contacts (either

Scientific Abstracts

27

simple or peg-in-socket) and intermediate contacts. These differences occurred with respect to layer of muscle and hormonal state. Nexuses were frequently found between fibrocytes adjacent to smooth muscle cells; this suggested that nexuses are not necessarily destroyed by our fixation and other procedures. If nexuses were not destroyed by our procedure, they were unnecessary for electrical coupling. The nature of these differences in distribution of other cell-to-cell contacts and their possible role in controlling electrical coupling in myo-metrium will be discussed.

(This research was supported by the Medical Research Council of Canada.)

46 Slow Entry into Blood of Estrone Produced in Extraglandular Site(s) in Obesity and Endometrial Neoplasia

CD. Edman and P.C. MacDonald 
Department of Obstetrics-Gynecology, University of Texas Southwestern Medical

School at Dallas, Dallas, Tex., USA

An increased conversion of plasma androstenedione to estrone - [p](AEl/BU) occurs in aging, hepatic disease, and obesity. However, 4-hour isotope infusion studies have failed to demonstrate total entry into blood of 14C-estrone formed from infused 14C-androsten-edione, i.e.

$[\rho](\mathrm{AEl} / \mathrm{BU})>[\mathrm{p}](\mathrm{AEl} / \mathrm{BB})$ at $4 \mathrm{~h}$ in obese subjects. This apparently incomplete entry of $14 \mathrm{C}-\mathrm{E} 1$ from infused 14C-A in such studies may be attributed to one or more events; i.e. (1) 14C-E1 produced in extraglandular sites is irreversibly metabolized in situ prior to its entry into blood; (2) 14C-E1 is immediately sulfurylated in site(s) of aromatiza-tion and enters the blood in part asElS04, or (3) 14C-E1, in part, is produced from plasma androstenedione in site(s) from which it is slowly released into plasma, e.g. adipose tissue. Long-term infusion of 14C-A (8-48 h) in six patients weighing 106-360 lb have yielded results strongly favoring the third alternative. The [p](AEl/BB) approximates [pj(AEVBU) in 7-31 h (depending on body weight) if a true 'steady' state equilibrium occurs between 14C-E1 plasma entry and 14C-A rate of infusion. This equilibrium in plasma is reached more slowly $(30 \mathrm{~h})$ in massively obese women and in only $7 \mathrm{~h}$ in a 106-lb girl. Thus, estrone produced from plasma androstenedione may enter plasma from its tissue site of origin very slowly in obese subjects. These data would suggest that adipose tissue may represent a principal site of aromatization. Further, these data clearly show that short-term infusions to ascertain transfer constants of hormones in blood may be misleading and subject to considerable error.

47 Calcium Pump in the Fetal Sheep Heart

Mary E. Carsten and Nicholas S. Assali

Department of Obstetrics-Gynecology, University of California, Los Angeles, Calif., USA

Morphologically and functionally, the fetal cardiovascular system is strikingly different from that of the adult. Fetal heart rate is twice the adult and the right ventricle is more dominant that the left. In the adult mammalian heart, the relaxation-contraction cycle mechanism depends on changes in the intracellular calcium ion $(\mathrm{Ca})$ concentration and its uptake into the sarcoplasmic reticulum (SR). The present studies were designed to investigate whether this same contractionrelaxation mechanism operates in the fetal lamb heart.

Society for Gynecologic Investigation

28

Cardiac fragmented SR was prepared from term fetal hearts by differential centrifuga-tion $(15,000-40,000 \mathrm{~g} \mathrm{X} 90 \mathrm{~min})$ and purified on a sucrose density gradient by techniques previously reported. Fragments from maternal hearts were prepared by the same techniques to serve for comparison. For characterization, several metabolic inhibitors were used. At $37{ }^{\circ} \mathrm{C}$ and in the presence of ATP, $\mathrm{MgCl} 2, \mathrm{CaCl} 2,45 \mathrm{Ca}$ and oxalate, both fetal and maternal SR preparations, took up Ca from the solution simultaneously with hydrolyzing of the ATP. Calcium accumulation as well as ATPase activity were found to be lower in the fetal cardiac preparations than in those from the mother. On the other hand, the yield of SR from the fetal heart was greater than that obtained from the mother, leading to a higher calcium uptake capacity in the fetal heart (capacity $=$ yield $\times$ uptake). Thus, the relatively low activity of the calcium transport system in the fetal heart at term is compensated for by an abundance of SR which may well serve as one of the mechanisms that sustain the high fetal heart rate.

(Supported by NIH.) 
48 The Effect of Exercise on the Distribution of Uterine Blood Flow in Pregnant Ewes Luis B. Curet and John H. Rankin

Department of Gynecology-Obstetrics, University of Wisconsin School of Medicine, Madison, Wisc., USA

Abstract withheld by request of the authors.

49 Studies of Bacterial Inhibition by Amniotic Fluid with a New Plate-Count Technique R.P.

Galask, B. Larsen and P. Schlievert

University of Iowa, College of Medicine, Departments of Obstetrics-Gynecology and Micrology, Iowa City, Iowa, USA

Previous studies by several investigators have shown that amniotic fluid (AF) is inhibitory for a number of bacterial species. The previous studies showing bacterial inhibition usually employed spectrophotometric changes as a measure of bacterial growth. Because of the uncontrollable variation with the use of spectrophotometric determination of cell growth, we elected to change to the viable plate count method. This necessitated the development of a semi-micro technique giving reproducible results on small volumes of AF. By this method, the ability of AF to inhibit E. coli varied considerably from patient to patient. Loss of inhibition by dilution of AF with distilled water to $10 \%$ of its original concentration was observed, confirming the previous spectrophotometric data. Reversal of inhibition was also seen with the addition of phosphate ion, suggesting the inhibitor is likely a basic polypeptide. The inhibitory capacity is also decreased by magnesium sulfate which is known to interfere with basic polypeptide and histone inhibitors. Inhibitory activity is destroyed when AF is treated with a high concentration of bacterial cells before assay. This loss of activity by adsorption of the inhibitor to the bacterial cell surface suggests a cationic nature for the inhibitor. Ultrafiltration studies indicate the inhibitor has a molecular weight of less than 10,000 daltons. Therefore, it appears that AF contains an inhibitory substance which is a cationic polypeptide of low molecular weight and different from inhibitors previously described in other body fluids.

Scientific Abstracts

29

50 The Origin of Amniotic Fluid Phospholipids

Jacques F. Roux and M. Frosolono

Case Western Reserve University, Cleveland, Ohio, and Albert Einstein College of Medicine, Bronx, N.Y., USA

The acetone precipitation of amniotic fluid phospholipids has been said to isolate specifically lung surfactant. For this reason, the concentration and fatty acid composition of lecithin (L) in acetone and non acetone precipitates were determined in 50 aliquots of amniotic fluids obtained at different periods of gestation. During pregnancy an increase in L/S ratio and in palmitic acid concentration was measured in both fractions. No significant differences in L structure can be detected. In other aliquots, sucrose gradient centrifugation was carried out - Frosolono et aí: J. Lipid. Res. 11: 439 (1970) - to isolate specifically surfactant material from amniotic fluid. Lecithin's fatty acid composition, hysteresis and stability index were determined on the extracted product. The data was compared to that obtained in similar extract of human lung, liver, amnios and placenta. The results show that amniotic fluid L is recovered entirely in the sucrose-treated fraction. Lung, liver and placenta have a high percentage of this surfactant-like material. No major differences in fatty acid composition of $\mathrm{L}$ is detected among tissues and fluid. Amniotic fluid hysteresis and stability index resembles that of lung tissue. The data demonstrates that the acetone precipitation of amniotic fluid phospholipids is unnecessary to isolate surface active 
material. Amniotic fluid L may originate from many fetal organs. This would explain the increase in amniotic fluid $\mathrm{L}$ concentration with fetal organ maturation, and the good correlation of $\mathrm{L}$ with gestational age.

51 Human Fetal Respiration. Fate of Hypaque and 51Cr-Labeled RBC Injected Simultaneously into Amniotic Sac

Johann H. Duenhoelter and Jack A. Pritchard

Department of Obstetrics-Gynecology, University of Texas Southwestern Medical

School at Dallas, Dallas, Tex., USA

Radiopacity of the gut, but not the lungs, following injection of Hypaque into the amniotic sac has led to the conclusion that the human fetus swallows, but normally does not breathe, in utero. However, 51 Cr-labeled maternal RBC, similarly injected, have been demonstrated to accumulate in the lungs. The apparent discrepancy raises two questions: (1) Is Hypaque inhaled, but rapidly cleared from the lungs, whereas slCr is not? (2) Did fetal distress, especially hypoxia, during the previously reported $51 \mathrm{Cr}$ studies account for the $51 \mathrm{Cr}$ in the lungs?

Hypaque and 51Cr-RBC were injected the day before delivery into the amniotic sacs of two fetuses with anomalies incompatible with extrauterine life. Radiopacity from Hypaque was prominent in the gut, but not the lungs, yet sl $\mathrm{Cr}$ was abundant in both. Whereas in each fetus, slCr equal to that in nearly $500 \mathrm{ml}$ of amniotic fluid accumulated in the lungs, Hypaque equal to that in less than $5 \mathrm{ml}$ of amniotic fluid, did so. Thus Hypaque did not produce lung radiopacity because it was exhaled, absorbed, or both. Consequently, lack of radiographic evidence of Hypaque in the lungs does not preclude inspiration of an appreciable volume of amniotic fluid by the fetus.

slCr-RBC were similarly injected into the amniotic sac prior to the second trimester abortion for malignant hypertension. Doppler-monitored heart action ceased $25 \mathrm{~h}$ later. Minimal $51 \mathrm{Cr}$ accumulated in the lungs. Moreover, in four second trimester abortions, insignificant $51 \mathrm{Cr}$ accumulated in the lungs when 5!Cr-RBC were similarly injected into the

Society for Gynecologic Investigation

30

amniotic sac just before anesthesia and hysterectomy. Thus, severe hypoxia induced no remarkable increase in fetal breathing.

52 Prostaglandins and the Onset of Parturition in Rats

Anna-Riitta Fuchs, Yuthana Smitasiriand Udom Chantaraksri

Department of Obstetrics-Gynecology, Chulalongkorn University, Bangkok, Thailand, and Biomedical Division, the Population Council, the Rockefeller University, New York, N.Y., USA Indomethacin (INDO) and other inhibitors of prostaglandin (PG) biosynthesis reportedly cause prolongation of parturition in rats. Lack of endogenous PGs could impair parturition performance by several mechanisms. Experiments were performed to assess the role of PGs in uterine contractility, luteal regression and oxytocin release in pregnant rats by recording intrauterine pressure changes and measuring plasma progesterone $(\mathrm{P})$ levels in samples collected daily from pregnant rats treated with INDO or vehicle oil daily, starting on day 20. Oxytocin (OT) or PGF2 $\alpha$ infusions were given intravenously on days 21 to 23. In INDO-treated rats, onset of parturition was delayed by $12 \mathrm{~h}$ on the average, and delivery of litter was often prolonged.

Parturition was induced by OT in control as well as INDO rats, but induction was successful 12.5 $\mathrm{h}$ earlier on the average, in control, than in INDO rats. Uterine contractions or response to OT were not reduced by INDO treatment. The rapid decline in plasma P occurring on day 21 in control rats was delayed, but not inhibited by INDO treatment. Treatment with PGF $2 \alpha$ on day 21 
reduced maternal and neonatal mortality significantly in INDO rats. It is concluded that PGs do not contribute significantly to uterine contractility in rats but that they do play a part in luteal regression and possibly in oxytocin release in this species.

53 Role of Prostaglandins in the Regulation of Uterine Blood Flow

Norberto A. Terragno, Alicia Terragno and David Pacholczyk

Departments of Pharmacology and Obstetrics-Gynecology, Medical College of Wisconsin, Milwaukee, Wisc., USA

Venous efflux of a PGE compound ('PGE') from the gravid uterus of the dog is as great as that from the kidney, an organ having one of the highest rates of prostaglandin synthesis. Uterine production of 'PGE' is associated with anomalous responses of the uterine vas-culature to angiotensin II and exogenous PGE2. In chloralose anesthetized dogs in late pregnancy, angiotensin II increased blood flow (electromagnetic flowmeter) to one uterine horn, used as an index of uterine blood flow (UBF), by $26 \%$ from a control of $73 \mathrm{ml} / \mathrm{min}$. Concomitantly, blood flow to the left kidney (RBF) decreased by $18 \%$ from $237 \mathrm{ml} / \mathrm{min}$, and mean aortic blood pressure (MABP) increased by $15 \%$ from $90 \mathrm{~mm} \mathrm{Hg}$. Concentrations of 'PGE' in uterine venous blood doubled from a control level of $0.26 \mathrm{ng} / \mathrm{ml}$ during infusion of angiotensin II. PGE2 infused into the aorta, at rates $(500 \mathrm{ng} / \mathrm{min})$ which increased $\mathrm{RBF}$, did not affect UBF, although bradykinin was capable of dilating the uterine vasculature. Indomethacin increased MABP by 21 $\%$ and decreased UBF and RBF by $41 \%$ and $23 \%$, respectively. 'PGE' concentrations in uterine venous blood decreased by greater than $70 \%$. After the administration of indomethacin, angiotensin II increased MABP by $14 \%$ from a control of $108 \mathrm{~mm} \mathrm{Hg}$, whereas postindomethacin UBF increased less, and RBF decreased more, in response to angiotensin. The anomalous response of the vasculature of the gravid uterus to angiotensin II and PGE2 may be explained by the high basal rate of uterine synthesis of PGE2, which is further increased by angiotensin II. Most importantly, a high rate of blood flow to the gravid uterus appears to be dependent on prostaglandin synthesis.

Scientific Abstracts

31

54 A New Acute Phase Protein and its Relation to Normal and Pathological HumanGestation

Eric Knox, Roger Cappel, Ann Schluederberg and Dorothy M. Horstmann Departments of Obstetrics-Gynecology and Epid-Pub Health, Yale University, School of Medicine, New Haven, Conn., USA

A new precipitating antigen, rho, was recently demonstrated in the blood of persons infected with rubella virus. Rho is a protein which migrates in the $\beta-1$ zone during electro-phoresis, and is measured by standard immunodiffusion techniques. Similar to other recognized acute phase proteins such as C-reactive protein (CRP), rho titers are elevated following a number of stimuli (collagen disease, rheumatoid arthritis, viral infection). Rho can be induced in cell culture by viruses other than rubella, and its titers are reduced by acti-nomycin-D. These in vitro experiments point to a probable cellular origin of the antigen. Sixty-five percent of normal adult sera contain low levels of rho $(\mathrm{GMT}=1.2)$. Between the thirty-second and thirty-eighth week of normal pregnancy, $100 \%$ of maternal sera contains rho in high titers $(\mathrm{GMT}=5.2)$. Serial observations indicate that rho does not begin to rise until after the twenty-eighth week of gestation. These findings contrast with the pattern of CRP, which is found in its highest titer early in pregnancy and subsequently declines in the second and third trimesters. When compared to normal pregnancy, rho appears earlier and achieves higher titers in pregnant diabetics (GMT = 
10.8), while levels appear to be decreased in women prior to delivery of post-mature infants $(\mathrm{GMT}=3.0)$. Rho is found in low titers in normal newborn cord sera $(\mathrm{GMT}=1.5)$. No elevation is noted in women taking oral contraceptive pills or in women studied serially at various stages of molar disease of pregnancy. Thus, the origin and biologic significance of rho titer elevations in pregnancy is not clear, but it may have prognostic implications.

55 Incorporation of Different Rat Precursors into the Rat Maternal Liver during Pregnancy T. Terry Hayashi and Kathleen MacFarlane

Department of Obstetrics-Gynecology, University of Pittsburgh School of Medicine, Pittsburgh, Pa., USA

The incorporation of RNA precursors $2 \mathrm{~h}$ post-intraperitoneal injection of $3 \mathrm{H}$-uridine, $3 \mathrm{H}$ cytidine and $3 \mathrm{H}$-orotic acid into the rat maternal liver was studied serially throughout gestation. Marked differences were observed among the precursors; uridine displayed the least and cytidine the greatest degree of incorporation. However, there was a dramatic and precipitious drop in the incorporation of all precursors on the twenty-first day of pregnancy, just prior to parturition. There were no measurable changes in the activity of the nucleolar and extranucleolar DNAdependent RNA polymerase systems during this period. Within $24 \mathrm{~h}$ postpartum the level of incorporation returned to earlier pregnant values. The amount of blood radioactivity, determined $2 \mathrm{~h}$ post-injection, remained fairly constant throughout the duration of pregnancy.

The labeling of the nuclear and cytoplasmic RNA varied with the precursor utilized. $3 \mathrm{H}$-uridine displayed its maximum incorporation within 10-15 min and leveled off to a steady but lower level of radioactivity by $2 \mathrm{~h} ; 3 \mathrm{H}$-cytidine reached maximum incorporation within $2 \mathrm{~h}$ and remained constant thereafter; whereas $3 \mathrm{H}$-orotic acid continued to increase throughout the period of study.

Studies are in progress to reproduce an animal model by administering various hormones to young male and virgin rats.

Society for Gynecologic Investigation

32

56 Cardiac Systolic Time Intervals in Fetal Monkeys

Yuji Murata, Chester B. Martin, jr. and Roy H. Petrie

University of Southern California Medicine Centre, Department of Obstetrics-

Gynecology, Los Angeles, Calif., USA

Factors affecting the cardiac systolic time-intervals were studied in fetal rhesus monkeys during the last third of pregnancy. The intervals from onset of ventricular depolorization to mitral valve closure $(\mathrm{Q}-\mathrm{Mc})$ and aortic valve closure $(\mathrm{Q}-\mathrm{Ao}=\mathrm{PEP})$ and from aortic valve opening to aortic closing $(\mathrm{Ao}-\mathrm{Ac}=\mathrm{VET})$ were determined from simultaneous FECG and dopplercardiogram (DCG) recordings. Fetal arterial blood samples were obtained from indwelling vascular catheters for $\mathrm{pH}$ and respiratory gas determinations. The studies were carried out at intervals up to 16 days after operation. Acute fetal respiratory acidosis was induced by maternal $\mathrm{C} 02$ inhalation; fetal hypoxia, by maternal inhalation of low Oj mixtures; and metabolic acidosis, by infusions of 0.15 TV HC1. Other studies were carried out during fetal distress in labor.

Q-Mc and Q-Ao were independent of heart rate. Q-Mc and Q-Ao increased slightly with increasing fetal age, reflecting greater QRS duration. There was a positive correlation between diastolic BP and the Q-Mc and Q-Ao intervals. A strong negative relationship was found between fetal $\mathrm{pH}$ and the Q-Mc and Q-Ao intervals ( $\mathrm{Q}-\mathrm{Ao}=-44.3 \mathrm{pH}+369, \mathrm{r}=0.88, \mathrm{n}=45$ ). $\mathrm{Q}-\mathrm{Mc}$ and Q-Ao were unrelated to $\rho 02$. Ao-Ac varied inversely with heart rate between 240 and 
150 b.p.m. Below this rate, there was no further prolongation of Ao-Ac. Ao-Ac changed inconsistently with $\mathrm{pH}$ and $\mathrm{p} 02$.

57 Respiratory Movements in Fetal Rhesus Monkeys

Chester B. Martin, jr., YujiMurata, Roy H. Petrie and Julian T. Parer University of Southern

California School of Medicine, Los Angeles County-University of Southern California Medicine

Centre, Department of Obstetrics-Gynecology, Los Angeles, Calif., USA

Fetal tracheal pressure was recorded continuously for prolonged periods (up to 35 days) in awake, restrained rhesus monkeys. Other measurements recorded included fetal blood pressure, heart rate, eye movements and EEG. Fetal arterial blood samples were obtained intermittently for determination of $\mathrm{pH}$ and respiratory gas tensions. The observations spanned the interval from approximately 115 days gestation until term.

Changes in tracheal pressure representing a variety of respiratory movements were observed. Isolated and repetitive gasping movements exceeded $30 \mathrm{~mm} \mathrm{Hg}$ negative pressure. Rhythmic and rapid irregular breathing movements of lesser intensities were also recorded. These breathing movements occupied two-thirds to three-quarters of the time in healthy fetuses, and were absent during fetal distress. Somatic and eye movements were more frequent and the heart rate and blood pressure more irregular during the periods of respiratory activity than during the intervening quiet times.

(Supported by grant No. 06406-01 from the NICHD, USPHS.)

$58 \quad$ Steroid Receptors in Hypothalamus and Pituitary

/. John Davies, Frederick Naftolin and Kenneth J. Ryan

Harvard Medical School, Department Obstetrics-Gynecology, Boston, Mass., USA

Abstract withheld by request of the authors.

Scientific Abstracts

33

59 Interceptive Activity of 16 $\alpha$-Bromoacetoxyprogesterone, an Affinity Labeling Steroid

Steven W. Clark and James C. Warren

Washington University School of Medicine, Department of Obstetrics-Gynecology, St. Louis, Mo., USA

A local delivery system was utilized to study interruption of post-placentation pregnancy in rats. Intrauterine insertion of control silastic gels in the right cornua on day 7 of pregnancy had no effect on fetal survival. 16 $\alpha$-Bromoacetoxyprogesterone (ló $\alpha$-BAP) at $820 \pm 67 \mu \mathrm{g}$ or $1,735 \pm$ $191 \mu \mathrm{g}$ was effective $(\mathrm{p}<0.02)$ in causing fetal resorptions as compared to controls, $1.50 \pm 0.42$ and $2.50 \pm 0.96 \mu \mathrm{g}$, respectively, versus $0.38 \pm 0.13$. No contralateral effect was observed with either dose of ló $\alpha$-BAP. Resorbed fetuses were in close proximity while viable fetuses were distant to the $16 \alpha$-BAP-containing gels, regardless of whether the gels were inserted in the upper or lower uterine region. Other affinity labeling bromoacetoxyprogesterone derivatives and the structural analog, 16 $\alpha$-acetoxyprogesterone did not cause fetal resorptions. When animals treated with $16 \alpha$-BAP during their first pregnancy were allowed to undergo a subsequent non-treated pregnancy, normal numbers of viable and nonviable fetuses were observed. Intrauterine application of $16 \alpha$-BAP significantly inhibited uterine uptake of systemically administered $3 \mathrm{H}$ progesterone in non pregnant rats, while $2 \alpha$-bromoacetoxyprogesterone had no such effect. In conclusion, 16 $\alpha$-BAP appears to be a competitive antiprogestogen which occupies and covalently bonds the progesterone receptor leading to exclusion of endogenous progesterone. This inter-ceptive agent is capable of locally interrupting early pregnancy in the rat and does not exhibit any prolonged deleterious effects upon reproductive patterns. 
(Supported by a subcontract, AlO/csd 2491, from the Population Council and by Research Grant AM-15708 from NIH.)

60 ACTH in Human Umbilical Cord Blood

Alan J. Winters, John C. Porter and Paul C. MacDonald

Department of Obstetrics-Gynecology, University of Texas Southwestern Medical

School at Dallas, Dallas, Tex., USA

Much evidence supports the view that increased adrenocortical secretion by the fetus is a major determinant in the initiation of labor. If so, increased ACTH secretion by the fetus could be important in controlling the onset of labor. To test this hypothesis, ACTH levels were determined by radioimmunoassay in cord plasma from fetuses delivered under different conditions during different stages of gestation. The results are as follows:

Source of cord plasmaACTH, $\mathrm{pg} / \mathrm{ml}$ No.

Spontaneous labor at term $\quad 145 \pm 7.71 \quad 335$

Cesarean section with labor at term $126 \pm 20.1$

Elective cesarean section without labor at term

Oxytocin-induced labor at term $121 \pm 18.4$

15

$136 \pm 25.2 \quad 10$

16

Fetuses (20-34 weeks) $234 \pm 29.2 \quad 8$

$\begin{array}{lll}\text { Fetuses (less than } 20 \text { weeks) } & 249 \pm 65.7 \quad 7\end{array}$

1 Mean and SE.

Society for Gynecologic Investigation

34

In 22 non-pregnant, non-stressed adults, the plasma levels of ACTH in the afternoon were $43 \pm$ 3.7. Thus, it is evident that ACTH levels in cord plasma are appreciably higher than those of adults. These moderately elevated levels of ACTH in fetal plasma may induce the hypertrophy seen in the fetal adrenal. The decline in the plasma ACTH levels in term fetuses to levels below those of younger fetuses indicates that a pre-natal surge in ACTH release may not occur in the human fetus prior to parturition.

61 Testosterone as a Perinatal Determinant in Rats of Hepatic Steroid Metabolism in Adulthood Tom Tabei and W. LeRoy Heinrichs

Department of Obstetrics-Gynecology, University of Washington School of Medicine, Seattle, Wash., USA

The gonadal control of hepatic oxido-reductases metabolizing neutral steroids at the $7 \alpha$ and $16 \alpha$ positions is of particular interest because of sex-linked differences that appear at puberty in rats (hydroxylation predominates in males; dehydrogenation in females). Castration of males during the neonatal period causes them to develop female type enzyme activities in adulthood. The capacity of testosterone propionate (TP) to induce normal metabolic patterns of adulthood has been studied with 14C-dehydroepiandrosterone (DHA) and hepatic microsomes obtained at 70 days of age from neonatally castrated animals of either sex. An SQ injection of TP, $50 \mu \mathrm{g}$, into castrated neonates significantly increased the accumulation of 16-keto-A5-diol and 7-keto-DHA in adult males, but not in females. An attempt to stimulate a male-type puberty produced a similar effect after neonatal castration and weekly treatment $(0.6-1.3 \mu \mathrm{g} / \mathrm{g}$ body weight), beginning at 25 . days of age. Neither regimen alone, neonatal nor pubertal TP, restored the formation of $16 \alpha-\mathrm{OH}-\mathrm{DHA}$ and As-triol characteristic of adult males. However $50 \mu \mathrm{g}$ TP at birth, followed by the additional administration of pubertal TP, stimulated the $16 \alpha$ - and $7 \alpha$-oxido reductions by both males and females. The formation of A5-diol was unaltered in either sex by these manipulations. Unlike the C-16 $\alpha$ or 7-fraki-formations, the hepatic DHA 17/3- 
hydroxysteroid dehydro-genase is therefore independent of testicular control. These data indicate that testosterone from the neonatal and the developing testis plays a significant role in the sexual differentiation of hepatic oxidative enzyme activities in the adulthood of males.

62 Immunological Studies of Lactoferrin and Immunoglobulins A, G, and M in Human

Endometrium

Olga Gutierrez and Gerald S. Bernstein

Department of Obstetrics-Gynecology, University of Southern California School of

Medicine, Los Angeles, Calif., USA

Studies were conducted using tissue specimens obtained from women with normal menstrual cycles who were having a hysterectomy for non-malignant diseases.

The endometrium used was in the secretory phase according to histological studies. The specimens were pooled, mixed with 0.9-percent $\mathrm{NaCl}$, homogenized at 35,000 r.p.m., and the saline extract was studied by immunodiffusion and immunoelectrophoretic analysis. Only one line of precipitation was observed with each of the following antisera: mono-specific antihuman lactoferrin specially prepared by selective absorption with plasma fractions, anti $\gamma-\mathrm{A}$, anti 7-G, and anti $\gamma$-M globulins.

Scientific Abstracts

35

The line corresponding to the lactoferrin in the $\alpha-2$ region did not appear when the mono-specific antiserum where previously absorbed with purified human lactoferrin.

These results confirm the presence of the iron coating protein and the immunoglobu-lins in normal secretory endometrium.

In both methods, the precipitation reaction occurred earlier and with a greater intensity when the saline extract reacted with anti $7-G$ globulin indicating that this component was present in a higher concentration in the specimens studied.

63 Sequential Changes in the Renin-Angiotensin-Aldosterone System in Normal andHypertensive Pregnancy

Myron H. Weinberger, Norman J. Kramer and Loren P. Peterson

Department of Medicine, Obstetrics-Gynecology, Indiana University School of

Medicine, Indianapolis, Ind., USA

The purpose of this study was to define the sequential changes of plasma renin substrate (PRS), activity (PRA) and aldosterone (PA) during normal pregnancy and to examine possible differences in this system during hypertensive pregnancy. Subjects studied included 85 normotensive and 37 hypertensive women from 6 weeks' gestation to delivery.

Progressive increases in PRS, PRA and PA were observed after the ninth to twelfth weeks in normotensives to levels 3-5-fold greater than those observed in pregnant hypertensives. However, at 19-30 weeks of gestation, hypertensives had higher PRA than their normotensive counterparts and after 31 weeks demonstrated significant $(p<0.01)$ suppression of PRA. Similar changes in PA were observed. Few observations were made before 31 weeks in hypertensives. These studies have defined the sequence of changes of PRS, PRA and PA in normal pregnancy and compared them with similar observations after the development of hypertension. Changes in PRS do not account for the observed differences in PRA between hypertensive and normotensive pregnant subjects. The observations further demonstrate suppression of PRA and PA in the last trimester in hypertensives and suggest a possible pathophysiologic role of this system early in hypertensive pregnancy.

These studies were supported by PHS grant HL-14159. 
64 The Estrogenic Capacity of Organochlorine Pesticides

Mary S. Forster, Ronald J. Gellert and W. LeRoy Heinrichs

Department of Obstetrics-Gynecology, University of Washington School of Medicine, Seattle, Wash., USA

The estrogenic capacity of o,p'-DDT as a uterotrophic agent has been confirmed by demonstrating its ability to reduce plasma gonadotrophin levels in castrated females and by producing the persistent estrous syndrome (PES) in neonatally-treated rats. In subsequent experiments, several homologs of DDT have been tested for their ability to inhibit the in vivo and in vitro specific binding of $3 \mathrm{H}$-estradiol $(8.7 \mathrm{X} 10-9 \mathrm{M})$ in uterine cytosol and nuclear fractions: o,p'-DDT and o,p'-DDE $(1.4 \times 10-4 \mathrm{M})$ inhibit in vitro binding, but o,p'-, m,p'-, and p,p'-DDD, p,p'-DDE, p,p'-DDT and DDA showed no inhibition. Oral treatment of pregnant dams (days 15-19 of gestation) with $10 \mathrm{mg}$ daily of o,p'-DDD, and o,p'-DDT and DDA was ineffective in producing the persistent estrous syndrome in the offspring. Treatment of pups with o,p'-DDD or o,p'-DDT, $1 \mathrm{mg}$ SQ daily $\times 3$, produced the syndrome in females but did not disturb reproductive development of males; DDA and o,p'-DDE were

Society for Gynecologic Investigation

36

ineffective. Plasma gonadotrophin (FSH and LH) responses to ovariectomy of adults with PES were blunted. These data confirm the estrogenic capacity of large amounts of o,p'-DDT in the uterus and central nervous system and demonstrate a selective 'estrogenic' effect of other organochlorine pesticides in these organs.

65 Arachidonic Acid in Human Amniotic Fluid and its Relationship to Labor

F. Michael Schultz, Paul C. MacDonald and John M. Johnston

Department of Obstetrics-Gynecology and Biochemistry, University of Texas Southwestern Medical School, Dallas, TX 75235, USA

The mechanism for the initiation of labor has not been established. Prostaglandin $\mathrm{Y}^{\wedge} \mathrm{a}(\mathrm{PGF} 2 \alpha)$ has been implicated and its concentration is known to be elevated in amniotic fluid during labor. PGF2û: is thought to be formed in the decidua and to diffuse into the AF. The precursor of PGF2 $\alpha$ is free arachidonic acid (C20:4) which is released from phospholipids in the 2 position by the action of phospholipase A2. The free fatty acids in AF from women in labor and from those not in labor, near term have been examined. The following results were obtained:

ng/mlSEM C16:0 C18:0 C18:1 C18:2 C20:4 Total

Not in labor $127 \pm 38179+38228 \pm 51129+4268 \pm 14657 \pm 116$

Labor $275 \pm 52265 \pm 25691 \pm 100289+39560 \pm 501,905 \pm 196$

All fatty acids were elevated in AF from women in labor. The most pronounced increase was found in the levels of the unsaturated fatty acids which are derived primarily from the 2 position of phospholipids. The single most striking increase was found to be arachidonic acid. The concentrations of PGF $2 \alpha$ in AF and lysophosphatidylcholine in the chorioamnion were also found to be elevated in labor. In a patient with fetal demise, not in labor, $1 \mathrm{~g}$ of arachidonic acid was injected into the AF. Thereafter, she promptly labored and delivered. These results are consistent with the postulate that the activation of phospholipase A2 with its attendant release of arachidonic acid from fetal membranes leads to the formation of PGF2 $\alpha$ which may be of primary importance in the initiation of uterine contractions. 66 Abnormal Maternal Temperature and Fetal Oxygenation Karlis Adamsons, Ronald E. Myers and Arsenio Comas-Urrutia 
Departments of Obstetrics-Gynecology and Pharmacology, Mount Sinai School of Medicine of the City University of New York City, N.Y., Laboratory of Perinatal Physiology, NINDS, NIH and the Department of Obstetrics-Gynecology, University of Puerto Rico, Puerto Rico Our previous work has demonstrated that under normal circumstances the body temperature of the human fetus is about $0.5^{\circ} \mathrm{C}$ above that of the mother, and that this temperature gradient increases with a rise in maternal temperature above normal values. The purpose of this study was to elucidate the effect of maternal hyper and hypothermia upon fetal vital signs and the state of fetal oxygenation. Eight pregnant rhesus monkeys, near term, were used. Under pentobarbital anesthesia, the uterus was opened and catheters were

Scientific Abstracts

37

inserted in the left carotid artery and in the amniotic space. The uterus and the abdominal wall of the mother were then closed. After a stabilization period during which fetal blood pressure, heart rate, intrauterine pressure, maternal blood pressure, maternal heart rate and deep colonic temperature of the mother were continuously recorded, and fetal and maternal blood samples had confirmed normality of fetal oxygenation, the maternal temperature was progressively lowered to $30{ }^{\circ} \mathrm{C}$. Blood samples of mother and fetus were obtained serially synchronizing the sampling with the times at which maternal temperature fell by $1{ }^{\circ} \mathrm{C}$. The maternal body temperature was then gradually elevated by special infrared heating device to $42^{\circ} \mathrm{C}$. Fetal and maternal blood pressures and heart rates were recorded continuously, and blood samples were obtained as outlined above. A direct, positive and nearly linear correlation was observed between body temperature and fetal heart rate over the range of $30-40{ }^{\circ} \mathrm{C}$. Neither hypo nor hyperthermia of these degrees had an adverse effect on fetal oxygenation. Increase of maternal temperature above $41.5^{\circ} \mathrm{C}$ resulted in rapid asphyxia of the fetus accompanied by collapse of the fetal cardiovascular system. It is concluded that maternal hyperthermia constitutes a serious hazard to the fetus.

67 Effects of Maternal Hyperoxia and Hypoxia on the Rhesus Monkey Fetus Studied in a Chronic Preparation

Benjamin T. Jackson, George J. Piasecki and Miles J. Novy

Boston University School of Medicine, Department of Surgery, Boston, Mass., and

Oregon Primate Centre, Beaverton, Oreg., USA

Fetal (F) carotid and jugular and maternal (M) arterial cannulas were implanted in monkeys of 130-140 days' gestation. At 2 and 5 days, postoperative, the mother was tranquilized with phencyclidine. Inspiration of air was alternated with $100 \%$ or $15 \%$ and $10 \% 02$. Blood gases, fetal heart rate (FHR) and pressures were monitored. Distribution of fetal superior vena caval return (SVC \%) was determined with radiolabeled microspheres. Results:

Neither hyperoxia nor hypoxia had a remarkable effect on fetal $\mathrm{pH}$ which averaged 7.335. FHR decreased $0-25$ with $15 \% 02$ and 30-100 with $10 \% 02$. SVC \% for lung was $22 \pm 2,39 \pm 8$ and $2 \pm 0.5$ and for placenta $60 \pm 3,42+5$ and $78 \pm 3$ with air, $100 \% 02$ and $10 \% 02$, respectively. Conclusions: (1) maternal hyperoxia leads to a significant increase in fetal p02 and 02 content: $\mathrm{M}$ and $\mathrm{F} 02$ content increase is similar, suggesting no uterine vasoconstriction; (2) maternal hypoxia results in proportionally greater reductions in F than M 02 content; (3) hypoxia is associated with fetal bradycardia of variable degree; (4) distribution of fetal SVC return to lungs and placenta is sensitive to, and varies reciprocally with, changes in fetal oxygenation.

(Supported by the John A. Hartford Foundation, Inc. and NIH grant No. HD-06195.) 


\section{Society for Gynecologic Investigation}

38

68 Immunoreactive Calcitonin in the Mother, Neonate, Child and Adult

Naguib A. Samaan and Garland D. Anderson

Section of Endocrinology, Department of Obstetrics-Gynecology, University of Medicine, Anderson Hospital and Tumor Institute and Hermann Hospital, Houston, Tex., USA

Abstract withheld by request of the authors.

69 The Serum Concentrations of Ø-Melanocyte Stimulating Hormone in Human Pregnancy and the Puerperium

1. G. Ances and S.L. Pomerantz

Department of Obstetrics-Gynecology and Biochemistry, University of Maryland,

School of Medicine, Baltimore, Md., USA

/3-Melanocyte stimulating hormone (MSH) has been measured in pregnant women and during the puerperium with the use of a sensitive tube radioimmunoassay technique which requires no prior extraction. The lower limit of detectability of MSH was $0.6 \mathrm{ng} / \mathrm{ml}$ of serum when $400 \mu \mathrm{l}$ was assayed. This peptide appears to rise progressively throughout pregnancy with its highest concentration at term. Measurable quantities exceeding maternal levels were observed in both cord blood and amniotic fluid, and elevated levels of /3-MSH were found in lactating women. The role and possible chorionic origin of MSH remain to be definitely determined, as well as the possible clinical use.

70 Evidence for a Physiological Role of Erythropoietin in Fetal Erythropoiesis E.D. Zanjani, L.I. Mann, A.S. Gordon and L.R. Wasserman

Department of Physiology and Medicine, Mount Sinai School of Medicine, New York, N.Y., Department of Obstetrics-Gynecology, Nassau County Medical Centre, New York, N.Y., and Department of Biology, New York University, New York, N.Y., USA

In prior studies - J. Lab. clin. Med. 74: 782 (1969) - fetal sheep were found to produce erythropoietin $(\mathrm{Ep})$ in response to anemic hypoxia. To determine whether Ep has a physiologic regulatory role in these fetuses, $3 \mathrm{ml}(1 \mathrm{ml} /$ day $)$ of rabbit serum containing antibody to human urinary Ep (HUE) was given by femoral artery catheter to each of five fetuses of about 120 days' gestation. One $\mathrm{ml}$ of this anti-serum neutralized 70 IU of HUE but only 22 IU of sheep plasma Ep. Three other fetuses received the same amount of the immune serum for 3 days. However, the anti-Ep activity of this serum was neutralized by treatment with goat anti-rabbit $\gamma$-globulin antibody (GARGG) before injection into the fetus. Another group of four fetuses were given normal rabbit serum. Twenty-four hours after the last injection, all fetuses received $30 \mu \mathrm{Ci} 59 \mathrm{Fe}$ and were sacrificed $36 \mathrm{~h}$ later. A significant decline in the percent RBC-59Fe uptake was found in fetuses receiving anti-Ep (4.16 \pm 1.3 versus $28.32 \pm 3.9)$. This was accompanied by reduced incorporation of $59 \mathrm{Fe}$ into the spleen $(0.79 \pm 0.1 \% / 100 \mathrm{~g}$ versus $1.7 \pm 0.3 \% / 100 \mathrm{~g})$ and marrow $(5.7 \pm 0.8 \% / 100 \mathrm{~g}$ versus $15.8 \pm 2.9 \% / 100 \mathrm{~g})$. Liver uptake of $59 \mathrm{Fe}$ was not affected $(18.3 \pm$ $2.8 \% / 100 \mathrm{~g}$. versus $19.9 \pm 3.4 \% / 100 \mathrm{~g})$. Reticulocyte counts dropped in fetuses given anti-Ep $(0.02 \pm 0.0 \%$ versus $1.8 \pm 0.2 \%)$ as did the number of marrow erythroid precursors. No significant difference in any of these parameters was apparent in the GARGG-treated group Scientific Abstracts

39

as compared to those receiving normal rabbit serum. These studies indicate that Ep plays a significant role in the regulation of fetal erythropoiesis. 


\section{Placental Transfer and Fetal Urinary Excretion of Gentamicin during Constant}

RateMaternal Infusion

Ralph E. Kauffman, Daniel L. Azarnoff and John A. Morris

Departments of Pediatrics and Pharmacology, University of Kansas School of Medicine, Kansas

City, Kans., and Department of Obstetrics-Gynecology, Chas. R. Drew Post Graduate Medical

School, Los Angeles, Calif., USA

Placental transfer and fetal urinary excretion of gentamicin was studied in mid-trimester goat and human previable fetuses during constant rate maternal infusion with the drug. Gentamicin was not detected in the serum of any of the goat fetuses, even when maternal serum concentrations ranged from $15.2 \mu \mathrm{g} / \mathrm{ml}$ to $20.9 \mu \mathrm{g} / \mathrm{ml}$. However, gentamicin was present in the amniotic fluid of four animals from which fetal urine was not collected. Gentamicin was also present in fetal urine collected from three animals. In contrast, human fetal central venous serum concentrations of gentamicin were $21-37 \%$ of those in maternal serum, following constant rate infusion of the mother. In addition, gentamicin was present in human fetal urine in concentrations two to three times those in fetal serum. Gentamicin crosses the human placenta more readily than the goat placenta and is concentrated and excreted by the mid-trimester fetal kidney. This study illustrates the inherent danger in extrapolating information obtained from animal studies of placental transfer of drugs, and emphasizes the need to conduct carefully designed, confirmatory studies, in human beings. Animal studies are necessary and useful, but information directly applicable to improved understanding and care of the human fetus must necessarily come from corroborative studies involving the human fetal-maternal unit.

72 The Efficacy of $17 \alpha$-Hydroxyprogesterone Caproate in Preventing Premature Labor John W.C. Johnson, Karl L. Austin, Georgeanna S. Jones and Theodore M. King Johns Hopkins University, School of Medicine, Department of Obstetrics-Gynecology, Baltimore, Md., USA The objectives of this double-blind prospective study were to determine in a high risk population: (1) the efficacy of $17 \alpha$-hydroxyprogesterone caproate $(17 \alpha-\mathrm{OH}-\mathrm{P}-\mathrm{C})$ in preventing premature labor, and (2) the relationship of urinary pregnanediol excretion values to premature delivery. Patients were randomly assigned either $17 \alpha-\mathrm{OH}-\mathrm{P}-\mathrm{C}(250 \mathrm{mg})$ or sesame in oil and received weekly intramuscular injections. Twenty-four hour urine pregnanediols were determined at 19 and 30 weeks of pregnancy. The duration of pregnancy was determined on the bases of menstrual data, obstetrical evaluation, and Dubowitz scores. Forty-three patients delivered; seven had cervical sutures placed. The incidence of prematurity (delivery at 36 weeks or less) was 0 in the $17 \alpha-\mathrm{OH}-\mathrm{P}-\mathrm{C}$ group and $40 \%$ in the placebo group $(\mathrm{p}<0.02)$. The mean duration of pregnancy and the mean birth weight in the $17 \alpha-\mathrm{OH}-\mathrm{P}-\mathrm{C}$ group $(38.6$ weeks \pm 1.6 $\mathrm{SD} ; 2,836 \mathrm{~g} \pm 412 \mathrm{SD})$ were both significantly greater $(\mathrm{p}<0.025)$ than that observed in the placebo group (35.2 weeks $\pm 6.7 \mathrm{SD} ; 2,361 \mathrm{~g} \pm 1,085 \mathrm{SD})$.

The perinatal mortality rate in the $17 \alpha-\mathrm{OH}-\mathrm{P}-\mathrm{C}$ group $(0 / 1,000)$ was significantly less than that observed in the placebo group $(270 / 1,000)(p<0.05)$. No significant differences were noted in urinary pregnanediol excretion values, according to medication or time of delivery. The statistical analyses (using Yate's adjustment for continuity) indicate that $17 \alpha-$ Society for Gynecologic Investigation 40

$\mathrm{OH}-\mathrm{P}-\mathrm{C}$ is effective in preventing prematurity. However, the pregnanediol excretion values do not support the hypothesis that progesterone deficiency predisposes to prematurity. 73 Development of the Mouse Blastocyst Following Injection with Newcastle Disease Virus 
Robert H. Glass, Patricia, G. Caiarco, T.P. Lin, Joan Florence and Jang Oh Yale School of Medicine, Department of Obstetrics-Gynecology, New Haven, Conn., and University of California, School of Medicine, Department of Anatomy, San Francisco, Calif., USA To study the effect of virus on subsequent development of the preimplantation embryo, Newcastle disease virus was injected into the mouse blastocele. Eleven of $272(4 \%)$ injected eggs transferred to recipient mice survived to day 17 of pregnancy. In contrast, $25.8 \%$ of blastocysts, injected with allantoic fluid or phosphate buffered saline before transfer, were fully developed at day 17.

When virus-injected blastocysts were cultured for 48 h, 47 of 66 degenerated, while 14 of 15 control-injected blastocysts appeared normal.

Electron microscopy of virus injected blastocysts cultured for $24 \mathrm{~h}$ showed viral budding from the surface of the trophoblast cells facing the zona pellucida. In addition, the cells contained filamentous aggregates thought to be nucleocapsid. After $48 \mathrm{~h}$ in culture the trophoblast cells also contained electron dense granules. There was some degeneration of trophoblast, and large numbers of pleomorphic viral forms were present. The inner cell mass did not show evidence of viral infection.

74 Effect of Estrogen and Progesterone on Pituitary Responses to Luteinizing HormoneReleasing Hormone (LH-RH) in Amenorrheic Women

Irwin E. Thompson, William C. Patton, Merle J. Berger and Melvin L. Taymor Department of Surgery (Gynecology), Peter Bent Brigham Hospital, Boston, Mass., USA

Synthetic LH-RH in a dose of $150 \mu \mathrm{g}$ was injected intravenously on two successive days in 15 women with secondary amenorrhea of hypothalamic origin and in eight women with secondary amenorrhea due to polycystic ovarian syndrome (PCO). Of those patients with hypothalamic amenorrhea, three received LH-RH injections only, five were treated with estradiol benzoate (E2) in addition, four were treated with aqueous progesterone $(\mathrm{P})$ and three were treated with E2 $+\mathrm{P}$, each steroid being administered at various dose levels by intramuscular injection $4 \mathrm{~h}$ after the first injection of LH-RH. Of the patients with PCO, two were treated with E2 in addition, three with $\mathrm{P}$ and three with $\mathrm{E} 2+\mathrm{P}$. The patients receiving successive LH-RH tests without steroids showed a similar response in both tests. The patients with hypothalamic amenorrhea showed a significant suppression of LH response in the second test after prior administration of E2, P and E2 + P. FSH response was also usually suppressed in the second test after administration of sex steroids, especially in these cases where a pronounced initial FSH response had occurred. In contrast, patients with PCO failed to show significant suppression of the second $\mathrm{LH}$ and FSH responses in some cases, and three showed augmentation of the second LH response after $\mathrm{P}$ administration. The results indicate a direct effect of $\mathrm{E} 2, \mathrm{P}$ and $\mathrm{E} 2+\mathrm{P}$ on the psponse of the pituitary gland to hypothalamic LH-RH in amenorrheic women, and that this $1 / 8 \tau$ ect in itself may be modified by differences in the endogenous hormonal milieu of the pituitarv.

Scientific Abstracts

41

75 The Clinical Utility of Measurement of the DHEA to Estrogen Conversion System Dynamics. A Potential Tool for Fetoplacental Status Assessment

Marcos J. Pupkin, David A. Nagey, Jarlath MacKenna, David W. Schomberg and Carlyle Crenshaw, jr.

Duke University Medical Center, Duke Hospital, Department of Obstetrics and Gyne-cology, Durham, N.C. 
The objective of this study was to evaluate the clinical utility of the dehydroepiandro-sterone (DHEA) loading test (DLT) in fetoplacental status assessment during the last trimester of human pregnancy.

In each of seven high-risk patients and one 'normal' obstetric patient, $25 \mathrm{mg}$ of DHEA was administered intravenously after control samples were drawn. Total serum radioimmunoassayable estrogen concentrations were then determined at $1 \mathrm{~min}, 2.5,5,7.5,10,15,30$, $60,90,120,180$ and 1,440 $\min (24 \mathrm{~h})$, after the DHEA injection. The antibody used has crossreactivities of $0.8,1.0$ and 0.05 with estrone, estradiol, and estriol, respectively. Preliminary data reduction shows a good correlation of pregnancy outcome with base-line and peak concentrations of total serum estrogens. Utilizing a mathematical model described in another abstract (Nagey et al, abstract No. 16), correlation of DHEA conversion rate, DHEA clearance rate and estrogen clearance rate with the outcome of the pregnancy has been demonstrated. A computer implemented cluster analysis of the model parameters yields a picture of patient similarities and differences that is a reflection of pregnancy outcome.

76 Androgen Concentrations in Rat Testicular Tissue and Plasma as a Function of Age

/. Robert Mueller and Billy Baggett

Department of Biochemistry, Medical University S.C., Charleston, S.C., USA

It has previously been observed that immature rat testes are capable in vitro, of converting testosterone (T) to $5 \alpha$-androstan-3 $\alpha, 17 / 3$-diol (A) with dihydrotestosterone as the intermediate. The reactions are catalyzed by a $\Delta 4-5 \alpha$-reductase and a $3 \alpha$-hydroxy steroid dehydrogenase, respectively. Testes from mature animals, however, are notably less capable of catalyzing these in vitro conversions. In this work, we have examined the physiologic significance of these observations by measuring the levels of $(\mathrm{T})$ and $(\mathrm{A})$ in testicular tissue and blood plasma of rats of varying ages. The pooled tissue samples were homogenized, made alkaline, extracted and purified by three thin-layer chromatographic steps. Final quantification was accomplished by competitive protein binding analysis. Small quantities of tritiated (T) and (A) were added to the initial tissue homogenates to correct for procedural losses. In testes of rats $26-31,36-39,47-52$, 57-63, 70-75 and 85-90 days of age, we found (T) concentrations of $11 \pm 0.8,24 \pm 6.2,80 \pm$ $9.1,77 \pm 5.6,57 \pm 8.9$ and $121 \pm 20.1 \mathrm{ng} / \mathrm{g}$ tissue, respectively. The (A) concentrations were found to be $14 \pm 1.7,8 \pm 0.9,26 \pm 2.7,8 \pm 2.2,4 \pm 1.5$ and $5 \pm 0.7 \mathrm{ng} / \mathrm{g}$ tissue for the same sets of animals. For the age groups noted, the blood plasma (T) levels were 43, 100, 218, 328, 329 and $275 \mathrm{ng} / 100 \mathrm{ml}$ plasma. Corresponding (A) levels were 55, 39, 32, 18, 12 and $13 \mathrm{ng} / 100 \mathrm{ml}$ plasma. These data show that the levels of (A) in testes and plasma of immature rats are higher, relative to the $(\mathrm{T})$ levels, than in these tissues from mature rats. This suggests that the reductase exerts an effect on testicular hormone secretion in vivo.

Society for Gynecologic Investigation

42

77 The Effects of Ritodrine on Maternal Metabolism

William N. Spellacy

Department of Obstetrics-Gynecology, University of Florida, Gainesville, Fla., USA

Either Ritodrine (R), a /3-adrenergic stimulant, or a placebo $(\mathrm{P})$ were randomly administered in a double-blind study to ten women in premature labor in order to stop uterine contractions. After a control period of $1 \mathrm{~h}$ of an intravenous saline infusion, either R or P were infused for $12 \mathrm{~h}$. The subjects then received intramuscular therapy for $24 \mathrm{~h}$ and then oral treatment. The intravenous dosage of R progressed from 100 to $350 \mathrm{~g} / \mathrm{min}$. Maternal venous blood samples were drawn on all women at half-hourly intervals during the infusion and analyses were made for glucose, 
insulin, glucagon, HPL, HCG, triglyceride, and cholesterol content. The mean glucose (mg\%) and insulin $(\mu \mathrm{U} / \mathrm{ml})$ levels were elevated by R, but HPL (jug/ml), HCG (mlU X 102/Пü), TG $(\mathrm{mg} \%)$ and cholesterol $(\mathrm{mg} \%)$ were not significantly altered as noted (*p significant):

Time, h

Glucose

Insulin

HPL

HCG

TG

$\mathrm{C}$

The $P$ caused no significant change in any of these parameters. The maternal carbohydrate alteration returned toward normal by $48-72 \mathrm{~h}$, despite continued $\mathrm{R}$ treatment. The ultimate effects of $\mathrm{R}$ upon the fetus by changes in maternal metabolism and uterine blood flow are unknown.

78 Effect of Oral Contraceptive Therapy on Vitamin A Blood Levels, Vitamin D3 and Drug Metabolism

Gregory J. Macuilla, Rubin Bressler, Dean E. Carter, Mark R. Haussler, M. Wayne Heine, C.

Donald Christian and DeWitt, S. Goodman

Department of Obstetrics-Gynecology and Pharmacology, University of Arizona, College of Medicine, Tucson, Ariz., and Department of Medicine, College of Physicians and Surgeons of Columbia University, New York, N.Y., USA

Chronic steroidal oral conceptive (SOC) therapy (Norinyl $2 \mathrm{mg}$ norethindrone, $0.1 \mathrm{mg}$ mestranol) of 1 month duration, inhibited the conversion of vitamin D3 to 25-hydroxy D3 in three female subjects. Two subjects treated with $0.1 \mathrm{mg}$ mestranol alone, showed no change in the vitamin D3 conversion. Six females were studied to ascertain the effect of 3 months of SOC therapy on vitamin A blood levels and on antipyrine and phenylbutazone metabolism. All six had elevated vitamin A blood levels after SOC therapy and three of six showed inhibition of antipyrine metabolism. Six others who had been on SOC therapy for 1-7 years were tested during and 3 months after terminating SOC regimen. All six had their vitamin A levels decrease after terminating SOC regimen and three of six showed that they had inhibited antipyrine metabolism while on SOC therapy. No characterizing effects on phenylbutazone metabolism were found.

Scientific Abstracts

43

79 Intra-Ovarian Pressure Recordings in Conscious Rabbits and the Effect of Gonado-tropins (hCG)

Pramuan Virutamasen and Anna-Riitta Fuchs

Department of Obstetrics-Gynecology, Chulalongkorn University, Bangkok, Thailand, and Biomedical Division, the Population Council, the Rockefeller University, New York, N.Y., USA Very small latex balloons filled with 0.02 to $0.04 \mathrm{ml}$ water were connected to thin polyethylene catheters and inserted into the ovarian stroma of mature New Zealand rabbits. The catheter was attached with nylon sutures into the lumen of the ampulla of the ipsilat-eral fallopian tube. The catheters were taken out through the flank and exteriorized through the skin of the neck to permit continuous recordings from unanesthetized animals. Intra-ovarian pressure was recorded in 25 rabbits and changes indicative of contractile activity was present in all. These occurred periodically, consisting of a series of contractions with an amplitude of $2-5 \mathrm{~mm} \mathrm{Hg}$ and an 
average frequency of 8 per min lasting from 2.6 to $3.6 \mathrm{~min}$, alternating with quiescent intervals of $15 \mathrm{~min}$ on the average. The ovarian contractile activity had no relation to tubal contractions. The pattern of intra-ovarian pressure changes was influenced by hCG injections and by the endocrine state of the ovary. Norepi-nephrine, PGF2 $\alpha$ and oxytocin stimulated ovarian contractile activity.

80 Hemoglobin Production in Response to Oral and Intravenous Iron in Women with Severe Iron Deficiency Anemia

Daniel E. Scott and Jack A. Pritchard

Department of Obstetrics-Gynecology, University of Texas Southwestern Medical

School at Dallas, Dallas, Tex., USA

Hemoglobin $(\mathrm{Hgb})$ production in response to oral and intravenous iron was quantitated in 47 women with menorrhagia-induced severe iron deficiency anemia after arresting uterine hemorrhage with parenteral estrogen + progestin (Deluteval $2 \mathrm{X}$ ). Hgb production rates were measured during the interval from start of therapy until the Hgb concentration increased to 10.0$10.5 \mathrm{~g} / 100 \mathrm{ml}$. The rates of increase in Hgb mass were measured using $51 \mathrm{Cr}$-labeled RBC and the normal rates of $\mathrm{Hgb}$ synthesis were calculated from the final blood volume:

Iron dextran given intravenously in excess of the amount needed to regenerate normal hemoglobin mass was no more effective than was 180-220 $\mathrm{mg}$ of oral iron given in 3 divided doses daily as ferrous sulfate, fumarate or gluconate. The rate of response to iron dextran given intravenously in excess plus oral iron in large doses ( $>200 \mathrm{mg}$ daily) was only slightly greater. Thus, the only disadvantages to be anticipated with use of simple iron salts Society for Gynecologic Investigation

44

orally to correct severe iron-deficiency anemia are: (1) gastrointestinal intolerance which was quite uncommon at the dosage level of $200 \mathrm{mg}$ per day, and (2) failure to take the medication as directed.

81 Scanning Beam Electron Microscopy Studies of Morphologic Changes of Bacteria Induced by Amniotic Fluid R.P. Galask, B. Larsen and P. Schlievert Departments of ObstetricsGynecology and Microbiology, Iowa City, Iowa, USA

Inhibition of bacterial growth by amniotic fluid (AF) has been demonstrated by a number of investigators. The present report illustrates the sequence of AF-induced changes in bacterial morphology, as demonstrated by scanning beam electron microscopy. Bacterial species studied included E. coli, P. aeruginosa, K. pneumonia, C. perfringens, S. aureus, and a streptococcus species. All were grown under optimal conditions for the particular organism. A lag phase starter culture of each organism was diluted to contain approximately 105 bacteria per $\mathrm{ml}$ and a $0.1 \mathrm{ml}$ aliquot was placed into either AF or control medium and incubated. At intervals of 2, 4, 6 and 8 $\mathrm{h}$, the bacteria were removed, fixed and prepared for study. Cellular morphology of each organism at each interval of study was compared with the corresponding control specimen. The first recognized effect was cellular elongation (up to five times control) with incomplete cell division, effects present by $2 \mathrm{~h}$ and maximal at $4-6 \mathrm{~h}$. Disruption of the cell wall was first observed at $4 \mathrm{~h}$ and increased progressively, so that 8-hour specimens contained large numbers of spheroplasts. Similar changes were observed with all organisms although some exhibited more marked effects than others. These data substantiate, on a morphologic basis, the previously described antibacterial properties of AF. The changes observed are strikingly similar to those 
reported in morphologic studies of bacteria incubated with various antibiotics, but this represents the first demonstration of alteration in bacterial structure by a body fluid.

82 The Effect of Chemotherapy on Cell Mediated Immunity and Blocking Factor in Ovarian Carcinoma

Ernest I. Kohorn, Jean M. Davis, Margalit B. Mokyr and Malcolm S. Mitchell Department of Gynecology, Medicine and Pharmacology, Yale University, School of Medicine, New Haven, Conn., USA

The effect of chemotherapy upon cell-mediated immunity (CMI) and serum-blocking factor (BF) to tumor associated antigens was studied in six patients with ovarian carcinoma. Patients were treated with combination chemotherapy consisting of cytoxan, vincristine, methotrexate and fluorouracil (MOFUCY) or with melphalan alone. CMI was measured by cytotoxicity of circulating lymphocytes against autologous or allogeneic tumor cells and BF was measured by the inhibition of cytoxicity by autologous serum. Studies were performed for 2 up to 18 months. Mean CMI before therapy was $50 \%$. CMI was depressed 3 weeks after the commencement of each course of MOFUCY, but recovered within 2 weeks, despite continuing weekly therapy with methotrexate and fluorouracil. The' decrease was most likely attributable to cytoxan while vincristine appeared to have no depressive effect. BF was present in one patient before therapy and was absent during a remission induced by MOFUCY, reappearing during subsequent relapse. Melphalan appears to benefit immunity,

Scientific Abstracts

45

in that CMI was either not reduced or was augmented in two patients, and was associated with the disappearance of BF in one of them. At these schedules, chemotherapy did not adversely affect the level of CMI which was the same at the end of many months of intermittent therapy as at the beginning.

83 Amniotic Fluid Parameters of Fetal Maturation in the Baboon (Papio cynocephalus) O. Ray

Kling

Department of Gynecology-Obstetrics, University of Oklahoma College of Medicine, Okla., USA

The phospholipid profile of baboon amniotic fluid was determined by TLC, and the major compounds identified include lecithin, sphingomyelin and phosphatidyl ethanol-amine. The total $\mathrm{L} / \mathrm{S}$ ratio, creatinine concentration, $\Delta \mathrm{OD}$ at $450 \mathrm{~nm}$, and lipid cell content was determined in baboon amniotic fluids from 90 to 176 days gestation. The mean values for the $\mathrm{L} / \mathrm{S}$ ratio and creatinine increased with gestational age showing a significant increase in concentration during late gestation. The mean L/S ratio, as well as individual serial determinations, indicate the baboon L/S ratio correlates with gestation similarly to the reported human data. The bilirubin $(\Delta 450 \mathrm{~nm})$ and presence of lipid cells in baboon fluid were found to follow the same patterns established for human gestation. These findings indicate that the baboon is a representative subhuman primate model for studying human fetal development and maturation.

84 Amino Acid Transport in Placental Slices

Henning Schneider and Joseph Dancis

Departments of Obstetrics-Gynecology and Pediatrics, NYU School of Medicine, New

York, N.Y., USA

Experiments with placental slices were performed in an attempt to separately analyze the major steps involved in amino acid transfer - uptake, tissue accumulation and release. Ten amino acids 
were selected for study. The results showed considerable variation, but certain patterns of response emerged. The uptake of the acidic amino acids (glutamate and aspartate) and serine was rapid (12-20 $\mathrm{nM} / \mathrm{min} / 100 \mathrm{mg}$ tissue) and continuous during the 1-hour incubation so that high gradients (intracellular concentration:extracellular concentraSociety for Gynecologic Investigation

46

tion, 12.3-34.2) were achieved. Efflux was evidently much less effective than uptake. In contrast, the uptake of the basic amino acids (lysine and arginine) was not as rapid (5-6 $\mathrm{nM} / \mathrm{min} / 100 \mathrm{mg}$ tissue) and tissue accumulation rapidly plateaued (gradient: $2.0-2.2$ ) indicating an efficient efflux system. The neutral amino acids (alanine, AIB, glycine) and proline displayed rates of uptake similar to the basic amino acids ( $4-8 \mathrm{nM} / \mathrm{min} / 100 \mathrm{mg}$ tissue), but continued to increase their tissue concentrations reaching more modest gradients than the acidic amino acids (4.9-8.2). Leucine was an exception in that the rate of uptake was slow $(1.4 \mathrm{n} \Lambda / \mathrm{min} / 100 \mathrm{mg}$ tissue) and efflux was extremely rapid so that the gradient commonly remained below one. It is planned to compare the performance patterns with slices to transfer across the placenta using an in vitro perfusion method in an attempt to determine the limiting factors in transfer rates and transplacental gradients.

The results with placental slices compare more closely to those reported with immature kidney slices, than with adult kidney.

85 Study of the Role of Sex-Hormone-Binding Globulin (SHBG) in Hirsute Women D.C. Anderson, M.O. Thorner and R. Fisher

St. Bartholomew's Hospital, London, U.K., and the Department of Reprod. Medicine, La Jolla, CA 92037, USA

SHBG is the principal binding-protein for testosterone (T) and related 17/3-hydroxy-androgens (17-OHA) in human plasma and exerts an important effect on their unbound concentrations; a fall in SHBG will lead to a rise in the unbound level. We have studied plasma levels of SHBG in hirsute women before and after therapy. SHBG was measured by reversed competitive proteinbinding (CPB) using 3H-dihydrotestosterone as ligand, and total plasma 17-OHA levels by CPB. Basal SHBG levels (table) in hirsute women were half normal, while mean 17-OHA levels were raised nearly 2 -fold $(\mathrm{p}<0.005)$. The ratio of $17-\mathrm{OHA}$ :SHBG, a simple index related to the unbound androgen concentration, was elevated (mean 4.8-fold) in 19 of 20 hirsute women. Measurement in undiluted plasma at $37^{\circ} \mathrm{C}$ by steady-state gel filtration also showed greater percent unbound $\mathrm{T}$ in 17 hirsute women $(1.68 \% \pm 0.52 \mathrm{SD})$. than in nine normal women $(1.09 \%$ $\pm 0.17 \mathrm{SD})$. The changes in 17-OHA and SHBG were the same in hirsute women with normal periods and those with amenorrhea. For treatment, 18 hirsute women were given prednisolone, Norlestrin (to suppress ovarian androgens and elevate SHBG) and triiodothyronine (to elevate SHBG) separately or in combination. A fall in $17-\mathrm{OHA}$ :SHBG ratio to normal could usually be achieved by combining prednisolone with either estrogens or triiodothyronine.

Subjects $\quad$ SHBG $(\mathrm{X}$ 1O-8 M)1 17-OHA $(\mathrm{ng} / \mathrm{ml}) 1 \quad$ 17-OHA/SHBG ratio1-2

Normal women $\quad(n=34) 6.90 \quad(n=34) 1.55 \quad(n=20) 0.76$

$(4.20-11.30) \quad(0.75-3.2) \quad(0.032-0.18)$

Hirsute women $\quad(n=35) 3.75 \quad(n=85) 2.90 \quad(n=35) 0.36$

$(2.05-6.75) \quad(1.45-5.7) \quad(0.110-0.87)$

Normal men $\quad(n=22) 3.20 \quad(n=83) 10.00(n=17) 1.20$

$(1.85-5.55) \quad(5.10-19.7) \quad(0.720-2.00)$

Back-transformed log means and $95 \% \mathrm{CL}$. 
Both expressed as molar concentrations.

Scientific Abstracts

47

86 Fetal Blood Sampling in utero

Carlo Valenti, Yuet Wax Kan, Richard Guidotti, Vito Carnazza and Ronald F. Rieder

Department of Obstetrics-Gynecology and Medicine, SUNY, Downstate Medical Center, Brooklyn, N.Y., and the University of California, Hematology Division, San Francisco, Calif., USA

Abnormalities of /3-chain hemoglobin $(\mathrm{Hb})$ can be detected in utero by the study of $\mathrm{Hb}$ synthesis in fetal blood $(\mathrm{Fb})$. Only $5 \mu 1$ of $\mathrm{Fb}$ are required and fetal $\varnothing$-chain synthesis can still be identified in samples mixed -with maternal blood. Thus, prenatal diagnosis of hereditary anemias is possible. Fb has been obtained from placental vessels under direct vision through an endoscope. Aspiration of anterior placentas can provide small samples of mixed fetal and maternal blood. Nineteen patients with anterior placentas were studied. In 11 of them the presence of Fb was rapidly determined by the particle size Coulter Counter Analyzer. In this way, $5 \%$ or more fetal cells can be detected. Smears from the same samples stained with Betke-Kleihauer method confirmed the findings. After aspiration, saline was instilled to interrupt pregnancy according to NY State Law. For identification of fetal globin chain synthesis, the mixtures of fetal and maternal blood were studied by means of $\mathrm{Hb}$ synthesis which is much more active in fetal than in adult red cells.

87 Variation in Pituitary Responsiveness to Multiple Stimuli during Different Phases ofthe Menstrual Cycle

Jeffrey Rakoff, Theresa M. Siler and Samuel S.C. Yen

Department of Reprod. Medicine, UCSD School of Medicine, La Jolla, CA 92037, USA

We have attempted to answer the question whether the cyclic output of pituitary gonadotropins and ovarian steroids is accompanied by a cyclic variation in the pituitary sensitivity of other trophic hormone release during the course of the normal menstrual cycle. Pituitary responsiveness was evaluated with an integrated functional test using sequential administration of an arginine infusion, followed $90 \mathrm{~min}$ later by an i.v. bolus of TRF ( $500 \mu \mathrm{g})$ plus LRF (150 $\mu \mathrm{g}$ ). Basal levels and release of LH, FSH, GH, PRL and TSH in response to these stimuli were assessed during early follicular (days 2-4), late follicular (days 9-11), and luteal phase (days 20-22) of the cycle in 11 normal women. Serum estradiol, estrone and progesterone were also measured to ascertain the phases of the cycle.

When compared with the early follicular phase, our data indicate that apart from a variation in LH response to LRF, no significant change occurred in pituitary release of FSH, GH, PRL or TSH between early and late follicular phases, but a marked attenuation of GH and PRL release was found during the luteal phase. This latter finding suggests that progesterone may exert an inhibitory action at the hypothalamic and/or pituitary site(s) for the release of GH and PRL.

88 Augmentation of Prolactin Secretion by Estrogen in Humans

Theresa M. Siler, Yoichi Ehara and Samuel S.C. Yen

Department of Reprod. Medicine, UCSD School of Medicine, La Jolla, CA 92037, USA

Evidence that estrogen promotes pituitary prolactin (PRL) secretion is afforded by the finding of an increased pituitary PRL content and serum PRL concentration following exogenous estrogen administration in rats. In humans, clear evidence for such a relationship is not available. The effect of estrogen on PRL-release was assessed in 12 experiments performed on 10 hypogonadal 
women. Ethinyl estradiol (EE) in small doses $(1 \mu \mathrm{g} / \mathrm{kg} /$ day $)$ induced a significant elevation of serum PRL levels within the first week of treatment. There

Society for Gynecologic Investigation

48

was a further rise until a plateau was reached in about 3-4 weeks to levels of more than three times the initial concentration. This was accompanied by a pattern of increased fluctuation as determined in samples obtained at 15-min intervals. These events are reproducible in the same individuals. The corresponding serum LH and FSH fell progressively to premenopausal levels at the fourth week of treatment. With large doses (400 $\mu \mathrm{g} /$ day). EE induced a more prompt elevation of PRL-levels within $36 \mathrm{~h}$ after initiation of treatment. At the end of 1 week of treatment the rise of PRL was significantly greater than that found during small-dose EE treatment to levels five times the initial concentration. A similar quantitative relationship was revealed in patients with hyperprolactinemia. These data represent the first clear demonstration of the augmentation of pituitary PRL-release by estrogen in humans. This positive feedback relationship appears to be dose dependent.

89 Catheterization of the Post-Ductal Pulmonary Artery of the Sheep Fetus in utero A.F. David Cole, Marcos J. Pupkin, David A. Nagey and Irwin S. Johnsrude Division of Perinatal Medicine and Department of Radiology, Duke University School of Medicine, Durham, N.C., USA A technique for study of fetal pulmonary hemodynamics in utero has been developed.

In five gravid ewes at 130-140 days gestation under spinal anesthesia, a hystereotomy was made over the fetal neck. In all five fetuses the carotid artery was catheterized. A balloon-tipped flowdirected catheter was inserted into the jugular vein and advanced through the right heart to the preductal main pulmonary artery. Attempts at advancing the catheter to the post-ductal pulmonary artery after bradykinin injection in three fetuses with mothers breathing 20 percent or $98+$ percent oxygen at 1 ATA were unsuccessful. Catheterization of the post-ductal pulmonary artery was successful in two fetuses following exposure of the mother to $98+$ percent oxygen at 3 ATA and bradykinin administration.

Pulmonary and systemic arterial pressures, wedge pressures and blood gases were monitored. In these two fetuses, cineangiography revealed information on blood flow and state of the pulmonary vascular tree.

1 ATA and 3 ATA and

20 percent $0298+$ percent 02

Ductus diameter/pulmonary diameter $1.115 \quad 0.876$

Time to opacify tree $(\mathrm{sec}) \quad 1.830 \quad 1.270$

Time to clear tree $(\mathrm{sec}) \quad 3.740 \quad 2.550$

Circulation times and ratio of diameters of ductus arteriosus to post-ductal main pulmonary artery are shown to be related to fetal blood oxygen tension.

90 Determination of Capillary Volume in Sheep Placenta

John M. Bissonnette and R.C. Farrell

University of California, Irvine, Department of Gynecology-Obstetrics and Division of

Perinatal Medicine, University of Oregon School of Medicine, Portland, Oreg., USA

Ten experiments were performed in near-term ewes using an in situ perfused umbilical circulation. One $\mathrm{ml}$ of plasma containing $0.625 \mathrm{mg} \mathrm{T}-1824$ (vascular indicator) and $10 \mu \mathrm{c}$ of Scientific Abstracts

49 
urea $14 \mathrm{C}$ or glycerol 14C (diffusable indicator) was rapidly injected into the umbilical artery and serial collections made from the umbilical vein. The outflow concentrations were measured in a spectrophotometer (T-1824) and liquid scintillation counter (14C) and scaled by dividing by the injected mass. The summation of the recovered diffusable indicator to that of the vascular indicator was $0.99 \pm 0.09$ (mean $\pm \mathrm{SD}$ ). The mean circulation time of the diffusable indicator $(\mathrm{t}$ diff. $=24.4 \pm 3.5 \mathrm{sec}$ ) was retarded relative to that of the vascular indicator ( $\mathrm{t}$ vase.$=17.2 \pm 2.9$ $\mathrm{sec})$. The peak outflow concentration of the diffusable indicator was less than that of the vascular indicator. Zero time ( $\mathrm{t} 0$ ) is defined as the transit time through vessels in which there is no separation of the diffusable and vascular indicators (non-capillaries), $t$ diff. - $\mathrm{t} 0 / \mathrm{t}$ vase. $-\mathrm{t} 0$ is equal to the ratio of intravascular and extra-vascular volume to intravascular volume. This latter ratio can be obtained from the ratio of the peak concentrations of the two indicators and a value for t0 determined. Capillary transit time ( $t$ cap.) is equal to $t$ vase. -10 and in these experiments was 7.9 $\pm 2.1 \mathrm{sec}$. Capillary volume is the product of umbilical blood flow and $\mathrm{t}$ cap. We obtained a value of $16.9 \pm 5.7 \mathrm{ml} / \mathrm{kg}$ fetal weight for capillary volume compared to $37.1 \pm 12.0 \mathrm{ml} / \mathrm{kg}$ fetal weight. For total intravascular volume in the umbilical circulation. (Supported by grant HD 06636-01 USPHS.)

91 Functional Delineation of Hyperprolactinemia and Galactorrhea

Gary W. DeVane, Theresa M. Siler and Samuel S.C. Yen

Department of Reproductive Medicine, UCSD School of Medicine, La Jolla, CA 92037, USA

Functional correlation between hyperprolactemia and amenorrhea-galactorrhea was made in 41 patients. Of 37 patients with elevated PRL levels, all had galactorrhea (with and without amenorrhea) except three who were either hypopituitary or prepupertal. PRL levels in these patients exhibited a marked episodic fluctuation with values varied from normal to 10 -fold above normal range, both during short-term (via 15-min sampling) and long-term (via multiple daily sampling) studied. Thus, the presence of hyperprolactinemia may escape detection when single random samples are evaluated. Another four patients with galac-torrehea had normal prolactin levels. Differentiation of hyperprolactinemia between hypo-thalamic versus pit nature and separation between functional and neoplastic causes was assessed by an integrated pituitary function test; responses and association and dissociation of pit release of PRL, TSH, GH, FSH and LH during sequential administration of arginine and TRF-LRF have afforded useful but limited information. In several patients tested, L-dopa failed to provide meaningful discrimination. However, together with other clinical variables, these patients may be separated into seven categories: (1) proven or suspected pit tumor $(\mathrm{n}=10)$; (2) documented hypothalamic destruction by tumor or trauma $(\mathrm{n}=4) ;(3)$ postpartum galactorrhea-amenorrhea $(\mathrm{n}=5) ;(4)$ postpill amenorrhea-galactorrhea $(\mathrm{n}=5) ;(5)$ hypothyroidism $(\mathrm{n}=7) ;(6)$ medication known to alter hypothalamic catecholamine $(n=6)$; $(7)$ secondary to manipulation $(n=4)$.

92 Maternal Hormone Levels in Prolonged Gestation

John C. Hobbins, Leon Goldstein and Joyce Hofchild

Yale School of Medicine, Department of Obstetrics and Gynecology, New Haven, Conn., USA

In an effort to determine which post date patients are truly postmature, 48 women whose pregnancies continued beyond 42 weeks were evaluated by various serum hormone measurements: HCS determinations by a simple immunodiffusion technique (validated by Society for Gynecologic Investigation

50 
radioimmunoassay) and radioimmunoassays of estrone, estradiol, estriol, and progesterone. Twelve of the patients delivered babies with the postmaturity syndrome; 'mild' postmatu-rity was diagnosed in eight babies; and 28 infants were normal by pediatric examination. The mean \pm SD HCS levels for each group were: $4.1 \pm 1.1,5.6 \pm 0.7$, and $7.4 \pm 2.9 \mu \mathrm{g} / \mathrm{ml}$, respectively. Not one of the 12 postmature pregnancies was associated with an HCS level above $6 \mu \mathrm{g} / \mathrm{ml}$. Four of the 28 normal pregnancies had HCS levels below $5 \mu \mathrm{g} / \mathrm{ml}$ (two of these had other evidence of placental compromise). A mean HCS level of $4.2 \mu \mathrm{g} / \mathrm{ml}$ was associated with postmature infants having 5-min Apgar scores below 7. Comparing mean values in normal and postmature pregnancies, there was a statistically significant difference in HCS levels ( $p<0.005), E 2$ :E3 ratio $(\mathrm{p}<0.02)$, and P:E3 ratio $(\mathrm{p}<0.01)$. No significant differences were noted in serum levels of progesterone, unconjugated estradiol, or unconju-gated estriol.

The results indicate that a single parameter, HCS determination by the above technique, is helpful in the management of post date pregnancies.

93 Adverse Reactions to Intravenous Iron Dextran

Daniel E. Scott, AS. Saltin and Jack A. Pritchard

Department of Obstetrics-Gynecology, University of Texas Southwestern Medical

School at Dallas, Dallas, Tex., USA

Iron dextran, $500 \mathrm{mg}$ iron in $10 \mathrm{ml}$, was injected intravenously 3,842 times as follows: Inject 1 $\mathrm{ml}$, observe $1 \mathrm{~min}$ and inject rest over $4 \mathrm{~min}$. Of the 2,584 recipients, $20 \%$ were pregnant.

One or more of the following reactions were identified for 291 patients and 313 injections (8.3 $\%$ ): in 149 instances pain at the injection site, typically brief and not severe; in 90: pruritus, flushing, or cutaneous eruptions; in 64: transient nausea, vomiting, dizziness, paresthesias, diaphoresis, tinnitus, headache, coughing, nasal irritation, dyspnea, or wheezing; in 56: fever subsequent to injection; in 20: arthralgia or myalgia; in 5: transient inflammation at site of injection or along the proximal vein. Reactions were not more common in pregnancy, than in those who previously had received iron parenterally.

The following reactions in four women (1:646) were more serious: (1) Syncope, tonic movements, hypotension and bradycardia treated successfully with metaraminol infused in lactated Ringer's solution. (2) Intense bronchospasm and bradycardia treated successfully with epinephrine, aminophylline, and diphenhydramine $\mathrm{HCl}$. (3) Chest pain, hypotension, and tachycardia treated successfully with an intravenous infusion containing metaraminol plus diphendydramine $\mathrm{HCl}$. (4) Stupor after injection with prompt clearing and normal vital signs as soon as recumbent.

Conclusion: Serious systemic toxicity from $500 \mathrm{mg}$ of iron dextran is rare when administered intravenously as described. Thus, the more persistent local and regional adverse reactions that commonly accompany intramuscularly injected iron dextran can, for the most part, be avoided. 94 Iron Stores and Prophylaxis in Pregnancies Complicated by Various Hemoglobinopathies

F. Gary Cunningham, Daniel E. Scott and Jack A. Pritchard

Department of Obstetrics-Gynecology, University of Texas Southwestern Medical

School at Dallas, Dallas, Tex., USA

Storage iron identified histochemically as Prussian blue in bone marrow aspirate was evaluated during 81 pregnancies in four groups of women with the following hemoglobino-

Scientific Abstracts

51 
pathies: SS, SC, S- 3 -thalassemia, and /3-thalassemia minor. There were 19-21 pregnancies in each group.

In general, the amount of storage iron correlated with the intensity of the hemolytic process. Storage iron was graded as $3+$ (approximately $600 \mathrm{mg}$ of iron based on previous quantitative phlebotomy studies) or more in $58 \%$ with SS disease, but in only $20 \%$ of those with SC disease and $15 \%$ with S-|3-thalassemia disease.

In $35 \%$ of pregnancies with SS disease, $57 \%$ with SC disease, $58 \%$ with S- $\varnothing$-thal-assemia disease, and $71 \%$ with $/ 3$-thalassemia minor, storage iron was judged inadequate to supply the requirements of pregnancy.

Sequential studies disclosed that, in general, those who expanded their total hemoglobin mass to any degree during pregnancy (measured by sl Chromium RBC labeling) also utilized some histochemically-identified storage iron even when iron was given prophylacti-cally $(<100 \mathrm{mg}$ iron/day). Moreover, patients who did not expand their hemoglobin mass seldom increased marrow storage iron significantly even though iron was given prophylacti-cally.

Conclusions: Iron supplementation prenatally can be of value in women with any of the four hemoglobinopathies under consideration. The benefits from prevention of anemia from lack of iron outweigh the theoretical possibility of inducing debility from iron overload.

95 The Log-Normal Distribution of Gonadotrophins and Ovarian Steroid Values in theNormal Menstrual Cycle

Oscar A. Kletzky, Robert M. Nakamura, Ian H. Thorneycroft and Daniel R. Mishell, jr. Department of Obstetrics-Gynecology, University of Southern California School of Medicine and the Los Angeles County-UCS Medical Center, Los Angeles, Calif., USA

Values obtained from RIA of serum gonadotrophins and steroids from groups of women are usually subjected to statistical analysis in order to determine the mean and the expected range ( \pm 2 SD). In some instances, the calculated values for the mean -2 standard deviations obtained by numerical calculations are either close to zero or negative. Since these negative values are statistical values only and cannot have any physiological reality, a rationale for performing such statistical evaluations was undertaken.

Accordingly, linear transform methods were utilized to investigate the nature of the distribution of data. Utilizing this technique of data analysis it was shown that the distribution of LH, FSH, $\mathrm{E} 2$ and $\mathrm{P}$ in various phases of the normal menstrual cycle was not normal (Gaussian) but was log-normal. The major departure of the values obtained from log-normal distribution when compared to normal distribution is the unequal values of the positive and negative standard deviations. For example, the -2 SD value used for luteal phase progesterone obtained by numerical calculation was $-0.7 \mathrm{ng} / \mathrm{ml}$ which is obviously incorrect. Utilizing linear transform, the same data had a $-2 \mathrm{SD}$ value of $+2.8 \mathrm{ng} / \mathrm{ml}$, similar to the expected clinical value. It is proposed that linear transform methods be utilized for all data analysis of groups of serum levels obtained by RIA.

96 Ultrastructural Observations on the Smooth Muscle and Connective Tissue in theUterine Myoma

I.M. Baccarini

Department of Obstetrics-Gynecology and Pathology, University of Chicago, Chicago, 111., USA

The 'hyalinization' of the collagen fibers increase greatly to the center of the leiomy-oma and the classical periodicity of the fibers is missed. Some fibrocytes show the chro-

Society for Gynecologic Investigation 
matin condensed at the nuclear membrane and the small cytoplasm contains very few scattered organelles. Other fibrocytes show advanced degree of degeneration and the compressed narrow cytoplasm contains rests of organelles and granular material. The smooth muscle cells show a variety of sizes which depend on the degree of degeneration. The nucleus, usually large, is centrally located with the chromatin, uniformly diffused. The number of filaments in the cytoplasm decrease in relation to the degree of 'hyalinization' of the cell; however, the paralleled orientation is preserved. A few mitochrondria are near the nucleus and small vesicles of the rough endoplasmic reticulum are seen scant in the cytoplasm. The normal pinocytosis characteristic of the smooth muscle cells are not seen, except in some cells of the external layers of the tumor. The basal lamina is seen in the peripheral cells of the tumor. The normal areas of attachments in which the plasma membranes of adjacent muscle cells are united, are not present because the cells are separated, one from another, by amorphous material. These observations demonstrate that the smooth muscle cells in the periphery of the tumor are almost similar to those of the normal myometrium. The size of the cells and the number of organelles decrease when the cell is undergoing regressive processes. The loss attachments from one cell to another suggest that excitatory impulses no longer exist in the leiomyoma.

97 Fatty Acid Composition of Lecithin from Baboon Amniotic Fluid as an Indication ofPulmonary Maturity

Robert V. Kotas, Robert D. Harlow and O. Ray Kling

W.K. Warren Medical Research Center, Tulsa, Okla., and University of Oklahoma Health Scientific Center, Department of Obstetrics-Gynecology, Oklahoma City, Okla., USA

Lipids were extracted from 30 baboon amniotic fluids obtained on nine animals between 115 days gestation and term. Lecithin was isolated by thin-layer chromatography and acetone precipitated. Fatty acids were converted to their corresponding methyl esters by acid catalyzed transesterification for quantification by hydrogen flame gas-liquid chromatography. As gestation proceeded, the percent of palmitic acid increased (40-80) while the percent of stearic (28-8) and oleic (30-13) decreased. The ratio of stearic to oleic acid increased (0.7-1.3) while the ratio of linoleic to palmitic acid decreased (0.09-0.02). The changes in fatty acid composition of lecithin from baboon amniotic fluid paralleled those reported in the human - Soc. Ped. Res. 7: 402 (1973).

98 Effect of Oral Contraceptive Agents and Mineral Vitamin Supplementation on Essential Metal Metabolism during the Menstrual Cycle

Earl B. Dawson, Mary J. Frey, Nina M. Monistere and William J. McGanity Department of Obstetrics-Gynecology, University of Texas Medical Branch, Galveston, Texas., USA

Serial blood and urine samples were obtained at weekly intervals from 30 young women $(<25$ years of age). One half were using oral contraception medication (OCA) and the other 15 women served as normal controls throughout the two menstrual cycles. Throughout the entire second menstrual cycle, each group ingested a mineral vitamin supplement (Natabec Rx).

Sodium, potassium, calcium, magnesium, copper, iron, and zinc levels more measured in the serially obtained blood serum and urine samples with a Perkin-Elmer 303 Atomic Absorption Spectrophotometer.

Scientific Abstracts

53 
Systematic alterations were noted in several of the metals throughout one and/or both of the menstrual cycles. The observed variations were associated with: (1) differences in the nutrient intake of the metal by the the two groups of women; (2) whether the women were taking the mineral vitamin supplement; (3) what day of the menstrual cycle the samples were obtained, and (4) whether the women were on an oral contraceptive agent.

Interaction between the serum and urinary levels of the several metals suggest that there are metabolic alterations which occur secondary to the ingestion of OCA medication.

99 Does Thyrotropin-Releasing Hormone Play a Role in Prolactin Release in Nursing Mothers? Kotaro Suzuki, Kaare M. Gautvik, lone Kourides, Bruce D. Weintraub, C. Thomas Graeber, Farahe Maloof, James E. Zuckerman and Armen H. Tashjian, jr. Harvard Medical School, Departments of Obstetrics-Gynecology, Medicine and Pharmacology, Boston, Mass., USA The control of prolactin release from the human pituitary gland is poorly understood. Thyrotropin-releasing hormone (TRH) is known to stimulate release of prolactin. In order to investigate whether or not TRH is the physiological mediator of prolactin release during suckling, we have measured serum levels of prolactin, TSH, T3 and T4 in seven postpartum women before, during and after breast feeding, and before and after administration of TRH. Suckling caused a consistent elevation of serum prolactin but had no effect on serum TSH, T3 and T4. Injection of TRH ( 6 and $300 \mu \mathrm{g}$ i.v.) elevated serum levels of both prolactin and TSH. One and 2 jug of TRH had no effect. No dose of TRH affected only one of the two hormones. Serum T3 and T4 did not change. Since lactotrophs are not consistently more sensitive to TRH than thyrotrophs, and since thyroid hormones did not rise acutely to block the response of thyrotrophs to TRH, we conclude that the selective increase in serum prolactin induced by suckling is not mediated solely through release of endogenous TRH.

100 Role of Fetal Deglutition in Production of Hydramnios in the Rhesus Monkey Lawrence J. Minei and Kotaro Suzuki

Harvard Medical School, Beth Israel Hospital, Department of Obstetrics-Gynecology, Boston, Mass., USA

In order to determine the exact role played by inability of fetal swallowing for production of hydramnios, we ligated the fetal esophagus in utero in five healthy monkeys in the second and third trimester, and measured the amniotic fluid volume daily over 10-22 days postoperatively. The sham operation was done in three monkeys in the similar gestation age. Esophageal occlusion was ascertained by amniography and fetal condition was assessed by daily monitoring of fetal heart rate. The fetal esophageal occlusion produced only transient hydramnios in the third trimester. The amniotic ñuid volume began to increase on the fourth postoperative day, continuing to increase gradually for the next 10-13 days, and then declined over the next 3-4 days. The maximum increase ranged from 100 to $280 \%$ of the preoperation volume, which was significantly more marked than that attributable to advance in gestational age and surgery (10-17 $\%)$. In the mid-trimester pregnancy there was no significant change in the amniotic fluid volume. Failure in fetal swallowing and ensuing transient hydramnios in the third trimester of pregnancy must be followed by readjustment in water exchange rates in other pathways, through which the amniotic fluid volume returns

Society for Gynecologic Investigation

54

to normal range. In the mid-trimester the fetal deglutition seems to have no appreciable effect upon the amniotic fluid volume control. 
101 The Operative Site Delivery of Cephaloridine Following Preoperative Intramuscular Administration in Healthy Pre-Menopausal Women

William J. Ledger, Carol Gee and William Lewis

University of Southern California School of Medicine, Department of Obstetrics-

Gynecology, Los Angles, CA 90033, USA

To determine whether systemic cephaloridine is secreted into the vagina to suppress surface

bacterial growth, concentrations of cephaloridine were determined in serum, vaginal mucosa, and vaginal washings of 13 women undergoing vaginal hysterectomy. Approximately $1 \mathrm{~h}$ before the operation each patient received $1 \mathrm{~g}$ of cephaloridine intramuscularly. The vaginal washings were obtained prior to the vaginal incision, while serum and vaginal specimens were collected immediately after removal of the uterus. Cephaloridine levels were measured by bioassay, using S. lutea as the indicator organism. No detectable cephaloridine was present in ten of 12 vaginal washings. In the other two specimens contaminated with menstrual blood, low levels of cephaloridine were present. Serum levels ranged from 14.2 to $42.6 \mu \mathrm{g} / \mathrm{ml}$ with a mean of 25 $\mu \mathrm{g} / \mathrm{ml}$ and exceeded vaginal tissue levels in every instance. Vaginal mucosa levels ranged from 10.3 to $40 \mu \mathrm{g} / \mathrm{ml}$ with a mean of $19 \mu \mathrm{g} / \mathrm{ml}$, which represents an effective antibacterial concentration of cephaloridine. Quantitative vaginal surface bacterial counts after uterine removal were done in 100 women who preoperatively had received $1 \mathrm{~g}$ of cephaloridine intramuscularly. Measurable quantities of bacteria were recovered from all but one of the patients. Results suggest that the clinical effectiveness of prophylactic antibiotics in vaginal surgery is dependent upon a therapeutic concentration of antibiotic at the incision site and not the elimination of surface bacteria from the operative site.

102 Topical Anesthesia of the Cervix and Uterine Cavity1

Robert A. Munsick

Department of Obstetrics-Gynecology, UNM School of Medicine, Albuquerque,

N.Mex., USA

The topical anesthetic efficacy of 1-percent tetracaine was tested on the clitoris, vagina and cervix, using as the endpoint the threshold voltage value of direct electric current to produce a tingling sensation. Under control conditions, tingling was not felt, even at $10 \mathrm{~V}$, in any of these three locations. Thus, only the exocervix, endocervix, and uterine cavity were studied, using a single-toothed tenaculum, Pratt dilators, and an IUCD for the respective locations, and judging the degree of discomfort felt on a $0-4$ scale for each. One percent tetracaine and placebo were compared in a double-blind manner on matched pairs.

1 Gratitude is expressed to Ian A.G. MacQueen, MD, Medical Officer of Health, Corporation of the City of Aberdeen Health Department, and especially to Eleanor M. Steiner, MD, and the Staff of the Family Planning Clinic in Aberdeen, Scotland, who performed most of the procedures; and to James F. Fuhlman, RPH, University of Indiana School of Pharmacy, who prepared and coded the tetracaine and placebo solutions.

Scientific Abstracts

55

There was no significant difference in the amount of pain felt between the tetracaine and placebo-treated subjects. It therefore seems unlikely that the use of topical anesthesia has any clinical value in these locations.

103 Interrelation of Carbon Dioxide and Water Transfer in the Placenta

Gordon G. Power and Lawrence D. Longo

Departments of Physiology and Obstetrics-Gynecology, School of Medicine, Loma 
Linda University, Loma Linda, CA 92354, USA

In an effort to understand the role of osmotic pressure in affecting placental water exchange we measured changes in volume of blood flowing out of a placental cotyledon as a function of fetal C02 level. We perfused the umbilical artery of a single sheep cotyledon in situ from a constant output syringe pump with whole blood equilibrated with widely varying pC02, and hence widely varying osmotic pressures. We collected and weighed outflowing blood samples during 10-min control (low C02) and experimental (high C02) intervals. We estimated water movement by the weight changes during passage of blood through the placenta. By subtracting control and experimental values, we could estimate water shifts caused by $\mathrm{C} 02$. In paired comparisons, water exchange increased in the maternal to fetal direction by $0.0012 \mathrm{ml} / \mathrm{min}( \pm 0.0004 \mathrm{SE})$ per $\mathrm{mm}$ $\mathrm{Hg}$ rise in $\mathrm{pC} 02$ and by $0.089 \mathrm{ml} / \mathrm{min}( \pm 0.02 \mathrm{SE})$ per mOs rise in osmotic pressure. The rate of water movement for an entire placenta with all cotyledons functioning would be about 100-fold greater. Our data therefore suggest that placental water movement is responsive to fetal $\mathrm{C} 02$ levels. We estimate, for instance, that a $5 \mathrm{~mm} \mathrm{Hg} \mathrm{pC02} \mathrm{rise,} \mathrm{if} \mathrm{sustained} \mathrm{over} \mathrm{an} \mathrm{hour,} \mathrm{would}$ lead to an increase in fetal water of $36 \mathrm{ml}$ (or about 1.3-percent increase in water space of a term fetus). Of course, during intrauterine life, fetal blood volume and cardiac output would be increasing in response to these water shifts and these and other compensations would affect longterm equilibrium values.

(Supported in part by USPHS grants HD 03807 and HD 04394.)

104 Maternal and Fetal Plasma Cortisol and Cortisone in Normal and Diabetic Pregnancy Sati C. Chattoraj, Jack L. Pinkus, Adrian K. Turner and David Charles Boston University School of Medicine, Department of Obstetrics-Gynecology, Boston, Mass., USA

Maternal, umbilical arterial and umbilical venous plasma, cortisol and cortisone were measured at vaginal and abdominal delivery. Maternal venous plasma samples were also analyzed during the third trimester. The third trimester levels of cortisol (F) and cortisone (E) (jug $\pm \mathrm{SD} / 100 \mathrm{ml}$ ) did not differ significantly between normal $(\mathrm{n}=26, \mathrm{~F}=24.6 \pm 10.6, \mathrm{E}=6.3 \pm 2.2)$ and diabetic $(\mathrm{n}=37, \mathrm{~F}=29.9 \pm 11.2, \mathrm{E}=7.1 \pm 3.8)$ subjects. No difference was observed among class $\mathrm{A}, \mathrm{B}$, $\mathrm{C}$ or D diabetic patients. At delivery, both cortisol $(\mathrm{p}<0.001)$ and cortisone $(\mathrm{p}<0.05)$ were higher in diabetics $(n=39)$ than normals $(n=52)$. In both normal and diabetic mothers, the $\mathrm{m}^{3} / 4 x i m a l$ levels of cortisol were noted at vaginal delivery. In normals, cortisol was higher $(\mathrm{p}<$ $0.001)$ in the umbilical arteries and cortisone $(\mathrm{p}<0.001)$ in the umbilical vein at vaginal and abdominal delivery. In diabetics, the arterio-venous difference of cortisol was similar to normals. However, no such difference was observed for cortisone. In addition, cortisone content in the arteries and vein differed significantly between modes of delivery (vaginal $>$ abdominal). (Supported by NIH grant No. HL 15157, Sickle Cell Anemia Center.)

Society for Gynecologic Investigation

56

105 The Use of Synthetic Luteinizing Hormone-Releasing Hormone (LH-RH) in the Differential Diagnosis of Secondary Amenorrhea

William C. Patton, Irwin E. Thompson, Merle J. Berger and Melvin L. Taymor Department of Surgery (Gynecology), Peter Bent Brigham Hospital, Boston, Mass., USA

Synthetic LH-RH was administered intravenously to 44 patients with secondary amenorrhea.

Serum FSH and LH levels were determined at 10-15-min intervals for $1 \mathrm{~h}$ before and $3 \mathrm{~h}$ after injection. Seven patients with organic pituitary disease and four patients with histories and findings consistent with anorexia nervosa, all had serum LH levels under $35 \mathrm{mlU} / \mathrm{ml} 30 \mathrm{~min}$ following LH-RH. There were no patients with either of these conditions among the other 33 
patients. All but two of these 33 patients had serum LH levels above $35 \mathrm{mlU} / \mathrm{ml}$ at $30 \mathrm{~min}$. These two patients had a mild form of congenital adrenal hyperplasia. One other patient with congenital adrenal hyperplasia had a serum LH above $35 \mathrm{mlU} / \mathrm{ml}$ at $30 \mathrm{~min}$. The remaining 30 patients included 19 with hypothalamic amenorrhea, nine with polycystic ovary disease, and two with premature ovarian failure. Polycystic ovary disease could be differentiated from hypothalamic amenorrhea by either a high base-line LH or a decreased response of FSH, or both, in the former, even though the LH responses were similar in the two groups. Two patients with premature ovarian failure were easily separated from the group by greatly elevated base-line FSH levels. The results suggest that a simplified 'LH-RH test' consisting of determinations of FSH and LH at 0,30 and 60 min following intravenous administration of LH-RH would be clinically useful in the differential diagnosis of patients with secondary amenorrhea.

106 Prolonged Inhibition of Gonadotrophin-Releasing Hormone

G. Betz, J. Stewart, K.L. Hill, M.J. Pfile and G.R. Matsueda

Department of Biochemistry and Obstetrics-Gynecology, University of Colorado

School of Medicine, Denver, Colo., USA

A new approach to inhibition of LH and FSH release from the pituitary has resulted from the discovery of gonadotrophic releasing hormone $(\mathrm{GnRH})$. This decapeptide is easily subjected to structure alterations which might inhibit, competitively, the effect of endogenous GnRH.

However, because of the short-term effects of most peptides, a molecule with prolonged activity is highly desirable for contraceptive use. Therefore, an analogue of GnRH with chlorambucil replacing the 1-pyroglutamate was prepared by solid-state synthesis. Hamsters maintained in a constant-light environment to establish a 4-day ovarian cycle were used as test animals. To test for agonistic effects the animals were blocked with phenobarbi-tal in proestrus, GnRH was administered $1 \mathrm{~h}$ later, and the animals sacrificed. The effect was quantified by counting ova. Synthetic GnRH demonstrated full activity while the chlorambucil analogue had no agonistic activity. Injection of $400 \mathrm{nM}$ of the analogue in proestrus without phenobarbital pretreatment was followed by sacrificing groups of animals 1,5,9 and 13 days later. Ova count revealed inhibitions of $43,19,25$ and $20 \%$ in cycles $1-4$, respectively. These inhibitions were highly significant compared to controls. It is assumed the inhibition is due to alkylation of pituitary GnRH receptors by attack on a nucleophilic residue such as histidine.

Note. A portion of this work has been presented at the International Union of Biochemistry, 1973, in Sweden. These data have also been recently submitted to Science for publication. It was felt that as these data in their entirety have not been presented in this country it would be appropriate to present them at this meeting. It is turned that publication will not precede the meeting.

Scientific Abstracts

\section{7}

107 Experience in Intrauterine Visualization and Fetal Blood Drawing

John C. Hobbins, Maurice J. Mahoney, Henry Chang and David Nathan Departments of Obstetrics-Gynecology, Genetics and Pediatrics, Yale University School of Medicine, New Haven, Conn., and Department of Research Hematology, Children's Hospital Medical Center, Boston, Mass., USA

The purpose of this project was to develop a method to view the intrauterine contents of patients in the second trimester in an effort to diagnose specific congenital anomalies, to obtain fetal skin biopsies atraumatically, and to draw fetal blood from the placenta. Utilizing a technique which combines the localizing properties of $\mathrm{A}$ and $\mathrm{B}$ ultrasonic scanning and the visualizing capacity of 
a small $(2.2 \times 2.7 \mathrm{~mm})$ solid optic endoscope, the intrauterine contents have been examined in 39 patients undergoing therapeutic abortion. In all of eight attempts, fetal blood has been obtained from vessels on the placental surface. Aspirated blood from the placenta contained 3-50-percent fetal cells, and amniotic fluid near the punctured vessel contained 80-100-percent fetal cells. In five of the mixed blood samples, fetal cells were separated and hemoglobin analysis $\left(<\mathrm{x}-, \mathrm{B}_{-}, 7-\right.$ chain synthesis) was performed. Skin biopsies, obtained in six cases, grew well in culture. The results indicate that antenatal diagnosis of hemoglobinopathies and perhaps many other inherited diseases is feasible by this technique.

108 Effect of Anencephaly and Fetal Tracheal Ligation on Amniotic Fluid Phospholipids in Rhesus Monkeys

Miles J. Novy, Oscar W. Portman and Mary Bell

Oregon Regional Primate Research Center, Beaverton, Oreg., and University of Oregon

Medical School, Department of Obstetrics-Gynecology, Portland, Oreg., USA

The specificity of amniotic fluid (AF) lecithin/sphingomyelin (L/S) as an index of fetal lung maturity is controversial. Total phospholipid (PL) and L/S were determined on unfrac-tionated $\mathrm{AF}$, on 1,000 g supernatant (AFS), and sedimented pellet (AFP) from 40 rhesus monkeys at 80 165 days' gestation and nine monkeys at 145-156 days with prior tracheal ligation or decapitation.

Early, there was little AFP with most PL in AFS. Later, as PL increased, L/S was greater in AFP than in AFS, and lamellar bodies similar in structure and dimensions to osmiophilic inclusions in type II pneumocytes appeared. Tracheal ligation or anencephaly produced normal AF PL;

reduced AF L/S; low AFP PL and L/S. There was patchy atelec-tasis without cystic changes and normal lung maturity after ligation, but anatomic immaturity after decapitation. There were no lamellar bodies in pellets from early fetuses or after ligation although tracheal fluid contained many lamellar bodies. We conclude: (1)AFPL occurs in epithelial cells, organelles, and lamellar bodies; (2) PL and L/S increase most in

Society for Gynecologic Investigation

58

AFP during maturation; (3) lamellar bodies in AF may be a more specific index of fetal lung maturity.

(Supported by USPHS grants No. HD-06159, HL-09744 and AM-08445.)

109 Hormone Responsiveness of the Placenta

Ruth Wade, Peter Walsall and David Gusseck

Loma Linda University, Obstetrics-Gynecology Research, Loma Linda, Calif., USA

Although the placenta has been traditionally viewed as an autonomous organ, it is becoming clear that it is capable of responding to a variety of hormones, thus suggesting that placental function may be subject to the endocrine status of the mother and fetus. We are using two parameters to measure placental hormone responsiveness. The first approach has involved incubating human placental tissue slices in the presence of hormones followed by an assessment of their cyclic AMP (cAMP) content. Epinephrine produces a maximal increase in cAMP of 350 $\%$ in 12 min at a hormone concentration of $5 \mu \mathrm{M}$. Human chori-onic gonadotropin (HCG) also yields elevated cyclic AMP levels with a maximal stimulation of about $150 \%$ being achieved 9 min after hormone addition (10 IU/100 mg tissue). This bears on the possibility that HCG may regulate placental steroidogenesis. We have been unable to demonstrate any effect of glucagon on the term placenta. Millimolar calcium in the incubation medium substantially reduces the 
epinephrine response of the slices suggesting that placental calcification may adversely affect hormone responsiveness. Our second experimental approach is to assess the effect of hormones on the induction of tyrosine aminotransferase (TAT), an enzyme involved with amino acid metabolism, in the rabbit placenta. The term-rabbit placenta has only about $2 \%$ of the TAT activity possessed by the maternal liver. However, the placental activity can be induced about $390 \%$ by an insulin injection given to the mother, and about $450 \%$ by hydrocortisone. This may be the first demonstration of enzyme induction by a hormone in the placenta and demonstrates placental responsiveness to insulin and an adrenal steroid.

(Supported by NIH grant No. HD 07036.)

110 The Computerized Prenatal Record as a Research ToolRichard J. Hildebrandt, Kevin C. O'Kane and Jean M. Weber

Pennsylvania State University Medical College, Department of Obstetrics-Gynecology, Hershey, Pa., USA

In order to investigate the pathophysiology of the Maternal/Fetal Unit, an accurate, wellorganized, legible medical record and a consistent data base with which to work should be available to the clinical and basic science researcher.

The prenatal records at the M.S. Hershey Medical Center have been computerized to achieve these objectives. The record is divided into seven categories: (1) Problem list -current and inactive. (2) Medications - current and inactive. (3) Computer-suggested problems (i.e. missing lab data, abnormal lab results, abnormal trends in blood pressure, etc.). (4) Treatment (including operative and diagnostic procedures). (5) Lab data. (6) Physical findings (vital signs, etc.). (7) Progress notes. All of the data base can be searched by the computer (with the exception of progress notes) with an average search time of $2 \mathrm{sec}$ per question asked. We currently have over 500 patients on the system with over 3 million bytes of information. The cost of keeping this information available 'on line' for research and clinical use is 13 cents per patient per month. Scientific Abstracts

59

111 Development, Comparison and Use of Specific Antisera for Plasma Estriol Radioimmunoassay

Hidehiko Katagiri, Frank Z. Stanczyk, Curtis L. Cetrulo, Roger K. Freeman and Uwe

Goebelsmann

University of Southern California School of Medicine, Department of Obstetrics-

Gynecology, Los Angeles, Calif., USA

Ease and success of antigen synthesis, antibody response, and plasma estriol (E3)

radioimmunoassay (RIA) development were compared for the two presently most promising E3 derivatives: E3-6-(0-carboxymethyl) oxime (E3-6-CMO) and E3 azobenzoic acid (E3-ABA). E3-6-CMO was purchased and E3-ABA synthetized. Both were linked to bovine serum albumin (BSA), incorporating $24 \mathrm{~mol} / \mathrm{mol}$ of BSA. Twelve rabbits were immunized, six with each antigen. All six E3-6-CMO-BSA rabbits, but only one E3-ABA-BSA animal, responded with useful titers $(1: 2,000-1: 10,000)$ within 15 weeks. All antisera showed little cross-reaction with estrone, estradiol and 16-epi-E3. E3-6-CMO-BSA (type 1) antisera cross-reacted some 70-220 $\%$ with 6-oxo-E3, and E3-ABA-BSA (type 2 ) antisera about $10 \%$ with 2-hydroxy-E3 , suggesting that this antigen must have been mainly or exclusively E3-4-ABA-BSA. Both types of antisera crossreacted appreciably with E3-3-sulfate. Third trimester pregnancy plasma (0.5 $\mathrm{ml}$ ) containing $3 \mathrm{H}-\mathrm{E} 3$ for recovery estimates was extracted consecutively with $3 \mathrm{ml}$ of 12 percent and $3 \mathrm{ml}$ of 40-percent ethyl acetate in $\mathrm{n}$-hexane. The residue of the latter extract was 
submitted to RIA using a type 1 and 2 antiserum, respectively. Whether or not celite column chromatography was included, both antisera provided identical results indicating that chromatography was unnecessary. Very little 6-oxo-E3 was detected in the extract. Coefficients of variation were 10.7 and $8.7 \%$ (intra-assay) and 9.5 and $11.2 \%$ (inter-assay) for the two antisera, respectively. Water and solvent blanks were un-detectable, and recovery of E3 added to male plasma was complete. Unconjugated plasma E3 averaged 7.2, 11 and $17.9 \mathrm{ng} / \mathrm{ml}$ at 29-32, 33-36 and 37-40 weeks of gestation, respectively. These results indicate that both routes yield antisera which are suitable for a rapid, yet specific, plasma E3 RIA, and that E3-6-CMO-BSA is the preferable antigen as it is more readily obtained and much more successfully provides E3specific antisera with useful titers.

(USPHS grant HD-05932 and Ford Foundation grant 690-0650.)

112 Radioimmunoassay of Plasma Estrone, Estradiol, and Estriol in Normal and Diabetic Pregnancy

Byron Holt, William A. McRoberts, jr. and Naguib A. Samaan

Section of Endocrinology and Department of Obstetrics-Gynecology, University of Texas Medical Department, Anderson Hospital and Tumor Institute and Hermann Hospital, Houston, Tex., USA

Estrone (E,), estradiol (E2), and estriol (E3) were measured in plasma by the radioimmunoassay technique through the course of pregnancy in 11 normal subjects, nine diabetic subjects who gave birth to live babies, two diabetics whose babies died soon after birth, and six diabetic patients who presented with intrauterine fetal death.

Plasma estrone and estradiol were within normal range in the diabetic patients who gave birth to live babies and showed the normal pattern of increase with time, but subnormal levels in those who had neonatal fetal death. However, serum estriol was low in all the diabetic patients studied except in two.

Society for Gynecologic Investigation

60

These data indicate that E, and E2 plasma levels may be of value in assessing the prospects of delivering a living infant, while the serial plasma E3 determinations in assessing feto-placental function in diabetic pregnancy should be interpreted with caution.

113 Male Pseudohermaphroditism Consistent with 17,20-Desmolase Deficiency

Uwe Goebelsmann, Val Davajan, Robert Israel, Jorge H. Mestman, Daniel R. Mishell, jr. and M. Zachmann

University of Southern California School of Medicine, Los Angeles, Calif., and Section of Endocrinology, University Children's Hospital, Zurich, Switzerland

A 16-year-old phenotypic female with XY genotype presented with short stature, prepubertal body contours, lack of breasts and axillary hair, scant pubic hair, a blind-ending vagina and absence of uterus and adnexa. Blood pressure and electrolytes were normal, serum testosterone (T) and estradiol (E2) below assay sensitivity and serum LH and FSH elevated to castrate levels. Two $1 \mathrm{X} 2 \mathrm{~cm}$ intraabdominal testes were removed revealing atrophic seminiferous tubules and Leydig cells without hyperplasia. Their karyotype was 46, XY. Serum gonadotrophins and urinary nitrogen excretion decreased in response to testosterone (26 mg q.d.). Suspecting a block in T biosynthesis on account of these findings, the following study of adrenal steroidogenesis was undertaken to identify the possible enzymatic defect. Prior to and following two 8-hour ACTH infusions on consecutive days, serum progesterone (P), 17-hydroxyprogesterone (T7OHP), cortisol (F), dehydroepiandro-sterone sulfate (DHAS) and androstenedione (A) was 
measured by radioimmunoassay as well as 24-hour urinary pregnanediol (Pdiol), pregnanetriol (Ptriol), pregnenetriol (5 $\Delta$ Ptriol), individual 17-oxosteroids, tetrahydro-11-deoxycortisol (THS) and THF by gas chromatography using glass capillary columns. Serum P, 170-HP and F levels were normal prior to and following ACTH, but serum A and DHAS were low and failed to respond to ACTH. All Pdiol, Ptriol, s $\triangle$ Ptriol and most individual 17-oxosteroid values were rather low. DHAS was barely detectable, even following ACTH infusion. THF was normal prior to and following ACTH. THS response was high, yet below that seen in 1lj3-hydroxylase deficiency. These results are consistent with 17,20-desmolase deficiency and suggest that an early step in the sequence of enzymatic events thought to constitute 17,20-cleavage may be affected.

(USPHS grant HD-05932 and Ford Foundation grant 60-0650.)

114 Alteration of Some Human Coagulation Components by Hormonal Contraceptives James R. Jones, Romeo J. Perez, JeffSolash and Philip Sawyer Department of OnstetricsGynecology, Brooklyn, N.Y., USA

Electrokinetic studies of blood cellular elements have indicated that a decrease in negative surface charge density (SCD) is an important factor in thrombogenesis. Changes in SCD can be monitored by measurement of the electrophoretic mobilities (EM) of platelets and rbc's. Using double-blind methods, the EM of platelets and rbc's were measured in the following four groups of women: group 0 (10 subjects) control, no chemical contraceptives; group I (16) medroxyprogesterone acetate (MPA), $150 \mathrm{mg} \mathrm{IM}$; Group II (10), ethinyl estradiol (0.05 mg) and Norgestrel $(0.5 \mathrm{mg})$; group III (10), ethinyl estradiol $(0.05 \mathrm{mg})$ and ethmodiol acetate $(1 \mathrm{mg})$. The mean \pm SD platelet $\mathrm{EM}(\mu \mathrm{cm} \mathrm{sec}-1$ volt -1$)$ of group 1

\section{Scientific Abstracts}

61

$(1.10 \pm 0.11)$ as compared to group $0(1.08 \pm 0.11)$ was essentially the same whereas groups II $(0.97 \pm 0.09)$ and III $(1.03 \pm 0.11)$ were significantly decreased. The mean $( \pm$ SD) rbc EM of group I $(1.36 \pm 0.09)$ as compared to group $0(1.42 \pm 0.07)$ was slightly decreased. The decreases noted in groups II $(1.30 \pm 0.10)$ and III $(1.33 \pm 0.08)$ were significantly lower than the group 0 but not different from group I.

These results suggest that estrogen-progestin combinations significantly alter the SCD of platelets and rbc's thus making them more conducive to thrombosis when compared to control subjects or subjects receiving only MPA. In support of this hypothesis, current-inducedocclusion data in rats with intraperitoneally administered estrogen-progestin combinations show a marked decrease in occlusion times for all compounds studied except the progestin MPA. 115 Estrogen-Androgen Imbalance in Patients with Hirsutism and Amenorrhea Dan Tulchinsky and Inder J. Chopra Department of Obstetrics-Gynecology, Boston Hospital for Women, Harvard Medical School and Department of Medicine, University of California, Los Angeles, Calif., USA Because of incomplete evidence regarding the circulating concentrations of free and bound sex steroids in patients with hirsutism and secondary amenorrhea measurements of the plasma concentration of unconjugated estradiol (E2), testosterone (T), dihydrotesto-sterone (DHT) by radioimmunoassay, percent unbound $\mathrm{E} 2$ and $\mathrm{T}$ by equilibrium dialysis at $37^{\circ} \mathrm{C}$, and serum concentration of sex hormone binding globulin (SHBG) by competitive ligand-binding assay were made in 12 such subjects. Only 3 of 12 patients had higher than normal serum T. The mean serum E2 of $41.6 \pm 6 \mathrm{pg} / \mathrm{ml}$ (SE) was only one-half that of follicular phase levels of normally menstruating patients ( 2 of 12 patients had subnormal E2 levels). The mean serum SHBG was 40 
$\%$ that of normal females. Consequently, the mean percent unbound plasma E2 and T were 30 and $60 \%$, respectively, higher than normal, while mean plasma concentration of unbound E2 was $40 \%$ lower, and that of $\mathrm{T}$ two times the mean follicular phase values in non-hirsute patients. Nine of 12 patients with hirsutism had higher than normal levels of unbound unconjugated $\mathrm{T}$ as well as subnormal unbound E2:T ratio. Of the other three patients, two had an abnormally low unbound E2:T ratio. Hypoestrogenism is common in patients with amenorrhea and hirsutism, and may potentiate the suppressive effect of T on SHBG and its promoting effect on hair growth and thus contribute to hirsutism.

116 Cardiovascular Effects of Prostaglandins on Fetal and Uterine Circulations of the Rhesus Monkey

Ronald E. Myers, Arsenio Comas-Urrutia, Lloyd A. LeZotte and Karlis Adamsons Laboratory of Perinatal Physiology, NINDS, NIH, Departments of Obstetrics-Gynecology and Clinical Pharmacology, University of Puerto Rico, and Departments of Obstetrics-Gynecology and Pharmacology, Mount Sinai School of Medicine of the City University of New York City, N.Y., USA

Recent years have witnessed an increasing interest in the use of prostaglandins for induction and stimulation of labor in the human. In view of the well-known capabilities of both PGF $2 \alpha$ and PGE2Ö to affect the cardiovascular system, it seems desirable to ascertain

Society for Gynecologic Investigation

62

the effects of these agents upon uterine circulation and the cardiovascular performance of the fetus following their administration to the mother or to the fetus directly. Twelve pregnant rhesus monkeys near term were used. Hysterotomy was performed under pento-barbital anesthesia and catheters were placed into the right fugular vein and in the left carotid artery of the fetus. An additional catheter was placed in the amniotic cavity and in the femoral artery and vein of the mother. Fetal and maternal blood pressures, and fetal heart rate and intraamniotic fluid pressures were recorded continuously on a polygraph. Fetal and maternal blood samples were analyzed periodically for $\rho 02, \mathrm{pH}$ and $\mathrm{pC} 02$.

Large doses of PGF $2 \alpha(5 \mu \mathrm{g} / \mathrm{kg})$ when injected intravenously into the fetus produced an initial hypertension, bradycardia and decrease in oxygenation, all of which were functions of the dose and duration of administration. The corresponding effects of PGE2 were hypotension, tachycardia, fall in $\mathrm{p} 02$ and rise in pC02. The effects of both prostaglandins upon cardiovascular function of the mother was similar, and both were capable in larger than therapeutic doses to produce profound decrease in fetal oxygenation. Evidence was obtained, that at least PGF, readily crosses the placenta. It is concluded that PGF $2 \alpha$ and PGE $2 \alpha$ in larger doses may adversely affect fetal oxygenation independent of their effects of the myometrium.

117 Arachidonic Acid in Human Amniotic Fluid and its Relationship to Labor

F. Michael Schultz, Paul C. MacDonald and John M. Johnston

Department of Obstetrics-Gynecology and Biochemistry, University of Texas Southwestern Medical School, Dallas, TX 75235, USA

The mechanism for the initiation of labor has not been established. Prostaglandin F2 $\alpha$ :PGF2a) has been implicated and its concentration is known to be elevated in amniotic fluid during labor. PGF $2 \alpha$ is thought to be formed in the decidua and to diffuse into the AF. The precursor of PGF2 $\alpha$ is free arachidonic acid (C20:4) which is released from phospholipids in the 2 position by the action of phospholipase A2. The free fatty acids in AF from women in labor and from those not in labor near term have been examined. The following results were obtained: 
All fatty acids were elevated in AF from laboring women. The most pronounced increase was found in the levels of the unsaturated fatty acids which are derived primarily from the 2 position of phospholipids. The single most striking increase was found to be arachidonic acid. The concentrations of PGF $2 \alpha$ in AF and lysophosphatidylcholine in the chorioamnion were also found to be elevated in labor. In a patient with fetal demise, not in labor, $1 \mathrm{~g}$ of arachidonic acid was injected into the AF. Thereafter, she promptly labored and delivered. These results are consistent with the postulate that the activation of phospholipase A2 with its attendant release of arachidonic acid from fetal membranes leads to the formation of PGF2 $\alpha$ which may be of primary importance in the initiation of uterine contractions.

Scientific Abstracts

63

118 Adrenal Function in Patients Receiving Medroxyprogesterone Acetate James R. Jones, Leonida DelRosario and Alice A. Soriero

SUNY, Downstate Medical Center, Department of Obstetrics-Gynecology, Brooklyn, N.Y., USA

Adrenal and pituitary function studies consisting of ACTH and SU-4885 stimulation tests were carried out on ten patients before and during medroxyprogesterone acetate (MPA) injections administered at 3-month intervals over the course of 1 year. Plasma cortisol concentrations and urinary excretion rates of 17-ketogenic (KG) and 17-ketosteroids (KS) were measured before and during the tests. The following observations were made: (a) base-line plasma cortisol concentrations were detectably lower after receiving MPA injections; (b) with ACTH stimulation, plasma cortisol and KG showed a normal, 3-5-fold increase, whereas the KS gave a variable response; (c) with SU-4885, the KG showed a somewhat blunted response, and again the KS were variable. There was also an indication that the SU-4885 blunting effect of MPA increases with time, up to 1 year. Thus MPA appears to suppress endogenous ACTH activity, but does not affect intrinsic adrenal function. These data are in support of the hypothesis, as described in a number of experimental animal studies, that MPA possesses significant glucocorticoid-like activity.

119 Pregnancy Hormones and Herpesvirus

Marvin S. Amstey and Sally Metcalfe University of Rochester School of Medicine, Highland Hospital, Department of ObstetricsGynecology, Rochester, N.Y., USA

A general clinical impression and some objective data indicate that genital herpesvirus infections are more severe and persist for a longer time during pregnancy. Several explanations are possible: an altered immune status, increased vascularity and blood flow, or increased viral infectivity due to one or more hormones elaborated during pregnancy. Studies presented here were directed toward investigating the latter possibility. Herpesvirus, type 2, strain EM was originally isolated from a pregnant patient with herpetic vulvovaginitis. The virus used in these experiments was never beyond its tenth passage in WI-38 cells. The virus was titrated in this cell system in the presence and absence of estriol, estradiol, HCG, HPL, and progesterone. The endpoint titers of this virus were greater when measured in the presence of estriol $(2.5 \mu \mathrm{g} / \mathrm{ml})$ and HPL $(10-20 \mu \mathrm{g} / \mathrm{ml})$. The one-step growth curves of this virus also were studied with and without the same hormones. Preliminary data indicate that HCG and HPL reduce the time period necessary for cellular production of infectious virus. Estradiol and progesterone seemed to have no effect on the end-point titers or the one-step growth curves for this herpesvirus. Very high 
concentrations of estriol tended to depress the final titers but did not affect the one-step growth curve. The specificity of the hormone effect on this virus was also evaluated.

120 Herpesvirus Infection in Pregnancy

Marvin S. Amstey

The neonatal outcome of disseminated herpesvirus infection is such that a mortality rate of 60 $90 \%$ and a severe morbidity rate of $15-30 \%$ may be expected. Appropriate management of pregnancies complicated by this genital viral infection will reduce these figures significantly. We have followed a plan or management that dictates abdominal deliv-

Society for Gynecologic Investigation

64

ery if a term or near-term pregnancy is complicated by genital herpesvirus infection and the membranes have been ruptured for less than $4 \mathrm{~h}$. Management was based on virologic data and not cytologic data. Using virus isolation techniques, 29 patients from the Universities of Rochester and Florida have been followed closely with a perinatal loss of 1/29 and a severe morbidity of $1 / 29$. A review of these data, in addition to 14 other patients who were delivered by cesarean section at a time when virus was being shed from genital lesions, confirms the increased risk with prolonged ruptured membranes. The details from these groups of patients will be presented. Newer therapies for infected infants have made their situation less hopeless. A description of vigorous therapy, with adenosine arabinoside and exchange transfusion for a newborn infected with herpesvirus, will be presented.

121 The Effect of Prostaglandin on Luteal Function in Pregnant Women

W.S. Michael Arrata and Robert T. Chatterton

Department of Obstetrics-Gynecology, University of Illinois, The Abraham Lincoln

School of Medicine, Chicago, 111., USA

T. The 1-uteolytic effect of prostaglandin F2 $\alpha$ has been well documented in a variety of animals.

This property has not

so far

been proved in women. Prostaglandin F2 $\alpha$ was administered directly into the uterine cavity extraovularly

to pregnant women

not exceeding 8 weeks' gestation. Serial blood samples were collected before

during

and after administration

for measurements of progesterone $(\mathrm{P})$

17-hydroxyprogesterone (17-OHP)

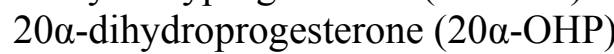

human Chorionic Somatomammotropin (HCS)

and prostaglandin levels. Our results indicate that PGF $2 \alpha$ successfully induces abortions up to 8 weeks gestation. Two mechanisms are involved: a mechanical and luteolytic. Initially the patients complained of severe low abdominal pains occurring within minutes of the intrauterine instillation as a result of a marked increase in intrauterine pressure. This in turn causes hypoxia in the fetoplacental unit. The steroid pattern showed a very gradual decrease in the $\mathrm{P}$ values initially with a 50-percent drop from the original values after the first $24 \mathrm{~h}$. One week after treatment the values are usually lower than $2 \mathrm{ng} / \mathrm{ml}$. There were slight changes in the $17-\mathrm{OH}$ values. The $20 \alpha-$ OHP values rose in the successfully treated patients by $30-50 \%$ within $24 \mathrm{~h}$ 
followed by a gradual decline over the next 3-4 weeks. HCS values declined rapidly almost to zero within hours of therapy. Prostaglandin acts primarily to cause fetoplacental hypoxia

as shown by the prompt decline in HCS

and secondarily on the ovary

as shown by the delayed decrease in serum progesterone accompanied by a transitory rise in $20 \alpha-$ OHP. 